NIST Special Publication 1129

\title{
Summary of the 2011 Workshop on Research Needs for Full Scale Testing to Determine Vulnerabilities of Decking Assemblies to Ignition by Firebrand Showers
}

Samuel L. Manzello

Sayaka Suzuki 
NIST Special Publication 1129

\section{Summary of the 2011 Workshop on Research Needs for Full Scale Testing to Determine Vulnerabilities of Decking Assemblies to Ignition by Firebrand Showers}

Samuel L. Manzello

Sayaka Suzuki

Fire Research Division

Engineering Laboratory

August 2011

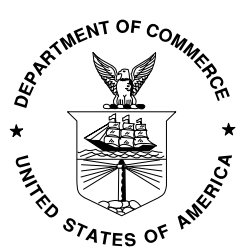

U.S. Department of Commerce Rebecca M. Blank, Acting Secretary

National Institute of Standards and Technology Patrick D. Gallagher, Under Secretary of Commerce for Standards and Technology and Director 
Certain commercial entities, equipment, or materials may be identified in this document in order to describe an experimental procedure or concept adequately. Such identification is not intended to imply recommendation or endorsement by the National Institute of Standards and Technology, nor is it intended to imply that the entities, materials, or equipment are necessarily the best available for the purpose.

National Institute of Standards and Technology Special Publication 1129 Natl. Inst. Stand. Technol. Spec. Publ. 1129, 67 pages (August 2011) 


\section{Table of Contents}

$\begin{array}{lr}\text { 1. Introduction } & 1\end{array}$

1.1 Objective of This Workshop 1

$\begin{array}{ll}1.2 \text { Session Agenda } & 1\end{array}$

2. Results of Discussions $\quad 2$

2.1 Exposing Deck Assemblies to Firebrand Showers 2

$\begin{array}{ll}2.2 \text { Summary } & 8\end{array}$

$\begin{array}{ll}\text { 3. References } & 10\end{array}$

4. Acknowledgements 11

$\begin{array}{ll}\text { Appendix1 Workshop Attendee List } & 12\end{array}$

$\begin{array}{lr}\text { Appendix2 Presentations } & 13\end{array}$

$\begin{array}{lr}\text { Appendix3 SFM Standard 12-7A-4 } & 58\end{array}$ 


\section{Introduction}

\subsection{Objective for this workshop}

The Engineering Laboratory (EL) at the National Institute of Standards and Technology (NIST) in Maryland has a research effort seeking a better understanding of disastrous Wildland-Urban Interface (WUI) Fires (http://www.nist.gov/index.html).

Firebrands are known to be a major cause of structure ignition of WUI fires in the United States (USA). To this end, NIST has developed an experimental apparatus, known as the NIST Firebrand Generator (NIST Dragon), to investigate ignition vulnerabilities of structures to firebrand showers [1-2]. The experimental results generated from the marriage of the NIST Dragon to the Building Research Institute’s (BRI) Fire Research Wind Tunnel Facility (FRWTF) in Japan have identified the vulnerabilities that structures possess to firebrand showers for the first time [3-4]. The detailed experimental findings are being considered as a basis for performance-based building standards with the intent of making structures more resistant to firebrand attack.

In support of building construction methods to reduce disastrous wildfire losses, NIST planning is underway for a new series of experiments scheduled to investigate the vulnerabilities of decking assemblies to firebrand bombardment using the NIST Dragon installed in the FRWTF at BRI in Japan. Input is desired for this experimental series from interested parties in California (e.g. building officials, Office of the State Fire Marshall (OFSM), code consultants, construction industry, and product manufacturers) since large WUI fires have occurred in this state recently. Specifically, guidance is desired in order to conduct experiments that will have the potential to provide the scientific basis for improvements for existing codes and development of new codes.

To this end, the Los Angeles (LA) Basin Chapter of the International Code Council (ICC; http://www.iccsafe.org) hosted a workshop on June 15, 2011 in Norwalk, CA. The workshop was moderated by Mr. Ruben Grijalva, former CALFIRE director and Mr. Stuart Tom, Certified Building Official (C.B.O.) from the city of Glendale, CA, served as the official note taker. Mr. Neville Pereira, LA Basin ICC Chapter President, arranged the venue and location.

This is a follow-up of the successful workshop held in 2010 to generate input for an experimental series focused on exposing siding treatments, glazing assemblies, and eaves to wind driven firebrand showers using the NIST Dragon [5]. Input was considered from that workshop to complete a series of full scale experiments in the fall of 2010. Results of those experiments were presented at recent conferences [6-7] and the June 2011 ASTM E05 research review [8].

\subsection{Session Agenda}

- Overview of the WUI problem in California, delivered by Mr. Ruben Grijalva, Former State Fire Marshal and Former CALFIRE Director (Presentation is provided in Appendix 2). 
- Overview of NIST WUI Research and in particular structure ignition research, delivered by Dr. Samuel L. Manzello, EL-NIST (Presentation is provided in Appendix 2).

- Summary of proposed experimental campaign to determine vulnerabilities to decking assemblies to firebrand bombardment using the NIST Dragon installed in the Fire Research Wind Tunnel Facility (FRWTF) at the Building Research Institute (BRI) in Japan, delivered by Dr. Samuel L. Manzello, EL-NIST (Presentation is provided in Appendix 2).

- Group input, discussion, and exchange of information.

\section{Results}

\subsection{Input related to importance of exposing decking assemblies to firebrand showers}

NIST presentation about decking assemblies is summarized below (see page 3). Since NIST considered many facets of decking assemblies, a series of questions was asked of the audience. Specific questions asked from the group included:

- Thoughts on type of wall assembly used to attach decking (vertical wall or reentrant corner)?

- How about the depth of the deck assembly?

- What about the height of decking assembly?

- Should the wall assembly be non-combustible in order to consider influence of deck only?

- What materials are most commonly used for decks in California?

o What is not commonly used?

- Are the profiles of the decking board important? Plank vs. Channel?

- What about the framing used to support the deck?

o What about ledger board to attach deck to wall assembly?

- What about deck board orientation, or patterns?

- Is a railing needed for the experiments? 


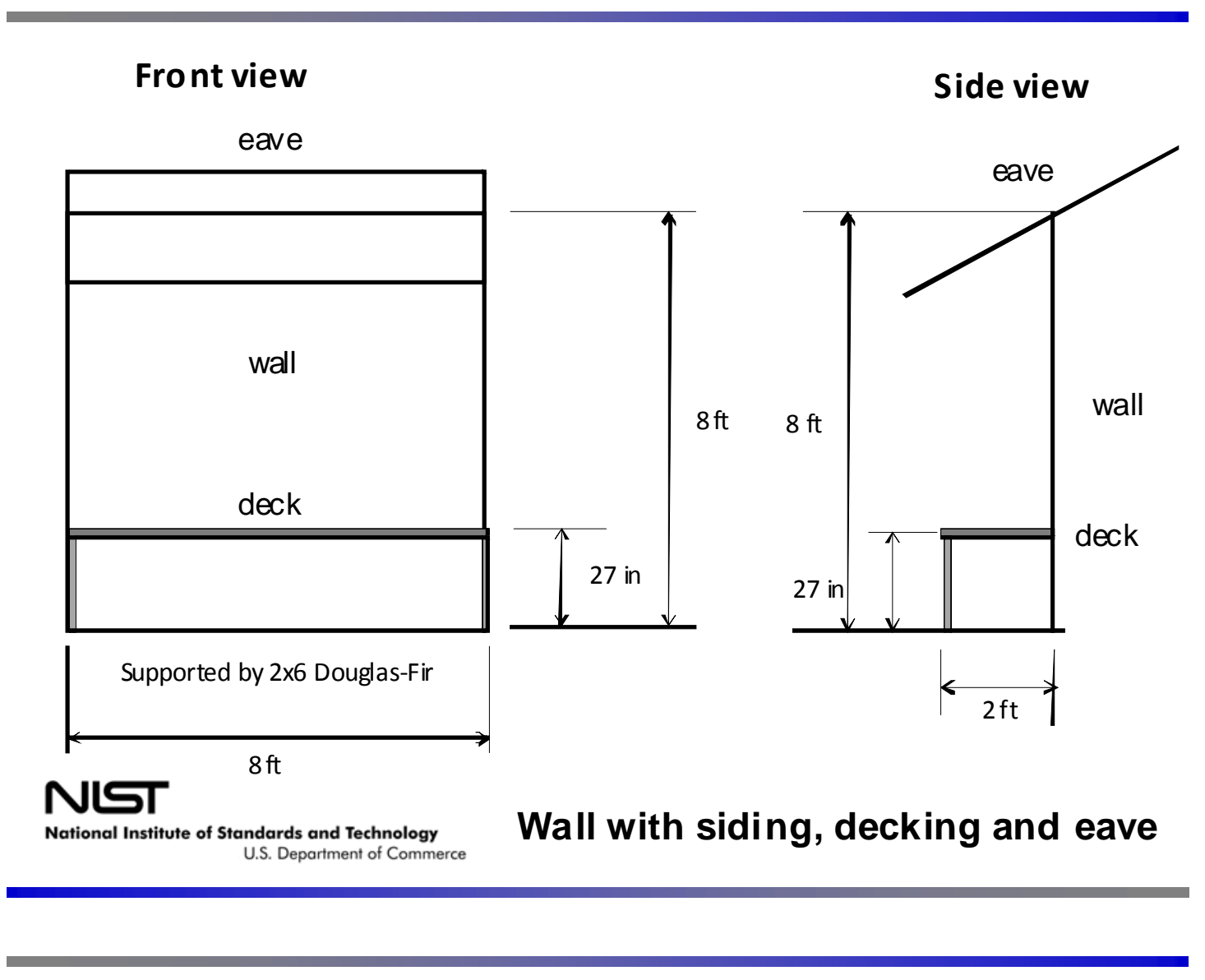

\section{Board Materials}

- Wood (treated wood or wood which is naturally resistant to decaying)

- Treated pine

- Cedar

- Redwood

- Ipé

- Composite

- Wood/plastic

- Fiber/PVC

- Plastic

- Metal

\section{NIST}

National Institute of Standards and Technology 


\section{Profiles}

Profiles---Depends on materials

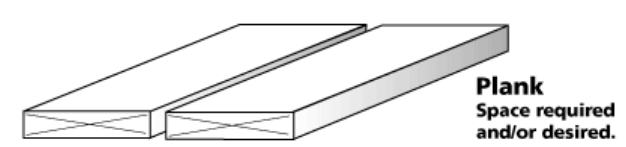

Plank---wood or composite

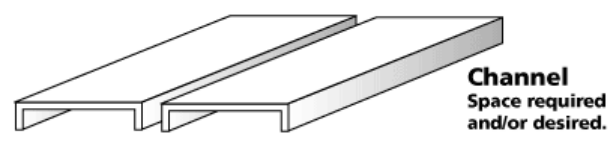

Channel--composite

\section{NLT}

National Institute of Standards and Technology U.S. Department of Commerce

\section{Framing}

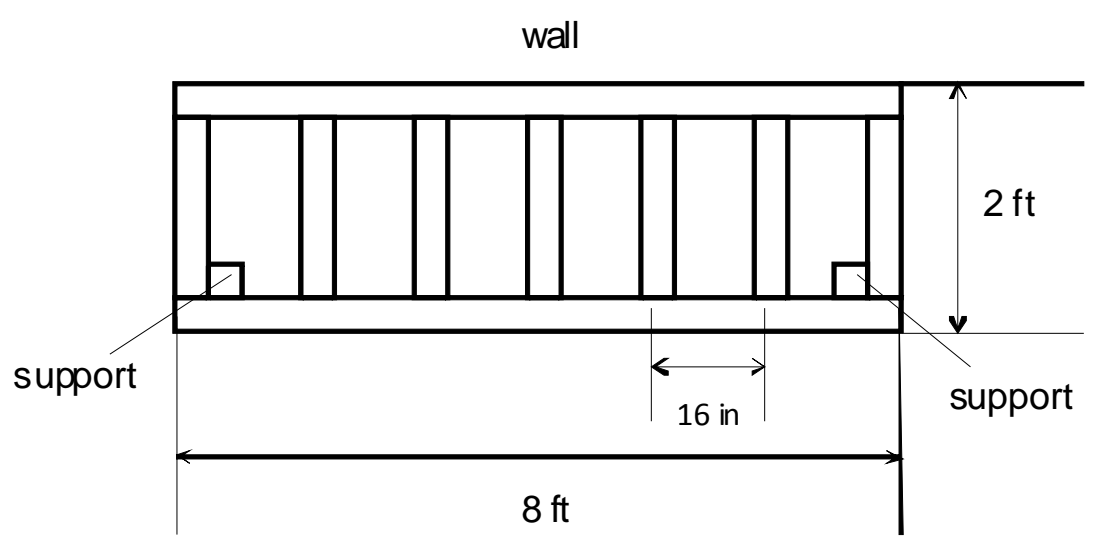

Made from $2 \times 8$

\section{NLT}




\section{Patterns}

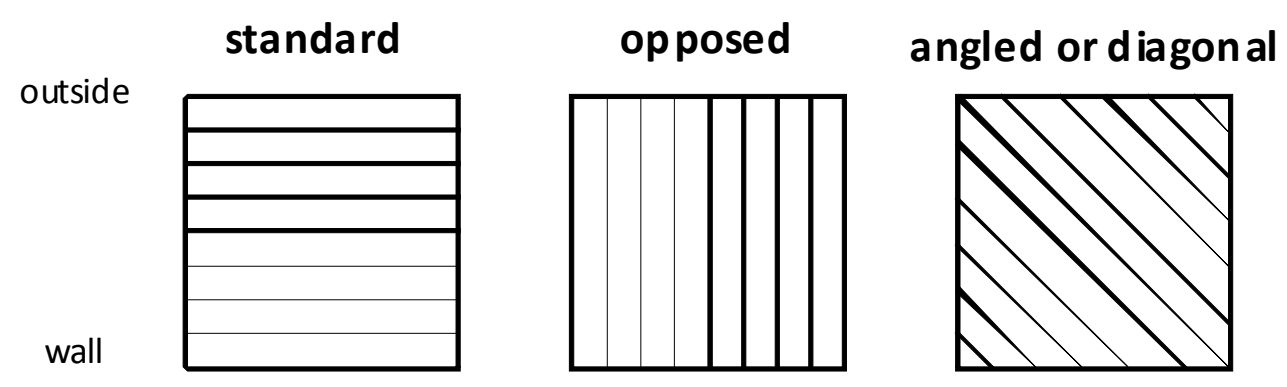

Which pattern is the easiest for firebrands to be stuck with? Or no difference?

\section{NLا}

\section{Railing}

- Railing is needed??

- If yes,

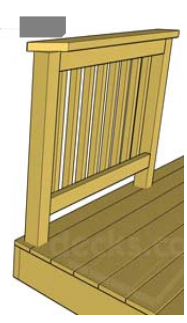

- surface of deck is 30 inches above the ground

- railing is 36 inches above the surface of deck

- a sphere with a diameter of 4 inches cannot pass through the space between each rail or any gaps
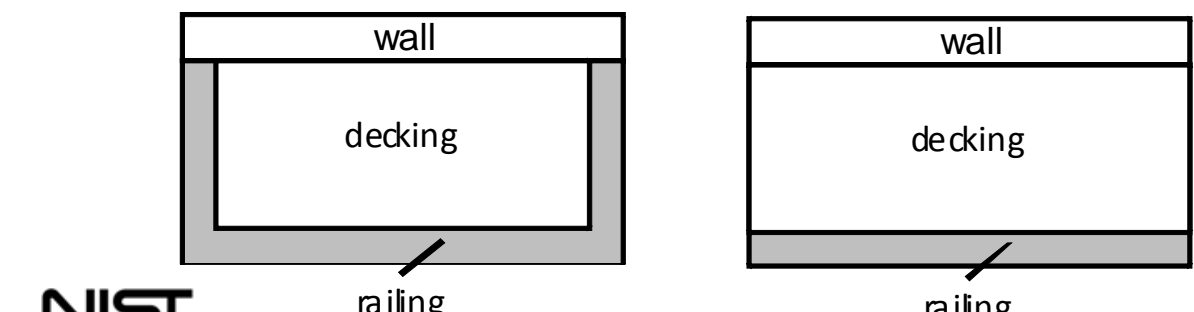

National Institute of Standards and Technology 


\section{Discussion and Input from Attendees (General Comments)}

The Office of the State Fire Marshall (OFSM) in California adopted the test method known as State Fire Marshall (SFM) STANDARD 12-7A-4 [9]. The current version, accessed from the California Building Standards Commission Website (http://www.bsc.ca.gov/default.htm), is reproduced in appendix 3.

- The focus of the group discussion was on the burning brand test; specifically SFM STANDARD 12-7A-4 Part B.

- The under deck test was not the focus of this workshop at this time.

- Before proceeding to the detailed discussion regarding testing input, some general comments were made as to what is the issue with the current SFM test method. Is new testing required?

- $\quad$ Regarding the SFM burning brand test, NIST made the following points:

o The SFM test method is intended to determine the response of decks to firebrand exposure.

o The simulation of firebrand exposure is very similar to the ASTM E108 [10] roofing test.

o ASTM E108 has been used for more than 100 years and brand exposure has never been revisited.

o Namely, a firebrand is simulated by placing a burning wood crib (either Class A, Class B, or Class $\mathrm{C}$ firebrand) on top of a section of a deck assembly under an air flow.

o Test standard does not simulate the processes observed in real Wildland-Urban Interface (WUI) fires.

o The dynamic process of multiple firebrands attacking decking materials as a function of time is not taken into account in this standard.

o Firebrand showers have been observed in actual WUI fires over and over again.

o Based on firebrand attack from real WUI fires, it is expected that multiple firebrands would accumulate within gaps/crevices of decking materials.

o In addition to not simulating a dynamic firebrand attack, no attempt is made to relate the size and mass of the firebrand used in this standard to actual firebrands produced from burning vegetation and structures.

o What evidence is provided to suggest that this test is a 'worst-case' firebrand exposure?

o Based on the development of the NIST Dragon technology coupled to a full scale wind tunnel facility at BRI in Japan, it is now possible to expose decking assemblies to wind driven firebrand showers.

o Recently, using the NIST Dragon, the danger of a dynamic firebrand attack has been demonstrated for ceramic tile roofing assemblies [3].

o Based on these experiments, it was observed that ceramic tile roof assemblies were vulnerable to ignition from a dynamic firebrand attack.

0 These experiments provided the first confirm of this vulnerability documented in the field [11]. 
o Another key issue is that the firebrand size and mass produced using the NIST Dragon has been tied to those measured from full-scale tree burns and an actual WUI fire [11].

o NIST conducts post-WUI fire damage surveys as well (work of Mr. Alexander Maranghides of NIST [12]); decks have been observed to be an ignition vulnerability based on post-fire damage surveys.

o NIST is interested in using the NIST Dragon technology to determine vulnerabilities of building components to wind driven firebrand showers.

o Before NIST developed the Dragon in 2006, no capability to expose building components to wind driven firebrand showers on realistic scale.

o NIST is interested in providing scientific basis for new building codes/standards.

o NIST Dragon Research has been focused on parametrically investigating building component vulnerability to wind drive firebrand showers.

- So far, experiments conducted for vents, eaves, siding, glazing in conjunction with observed vulnerabilities seen in post-WUI fire surveys

- Participants pointed out that:

o SFM standard testing did not necessarily do a good job simulating actual fire storm conditions.

o ASTM E-108 - Class “A” firebrand is not an ember.

0 Individual embers behave differently than standard brands (Class $A / B / C$ brands are wood cribs; see ASTM E108 [10]).

o Showers of embers behave differently than standard brands.

o Accumulation, intrusion, etc, are different ignition mechanisms.

o Chapter 7A of the California Building Code [9], where the decking test is listed, was the best that was possible based on the information that was available at the time.

o At the time that Chapter 7A [9] was developed, discussion occurred and consensus was reached with regard to the test method.

o Also at that time, there was an agreement that new research and science needs to be utilized to either substantiate that test method or modify the test method.

o NIST now has the capability to compare the SFM brand test to NIST Dragon and understand differences.

\section{Discussion Input from Attendees (Specific Deck Testing Comments)}

- NIST subsequently presented plans for decking experiments; detailed comment follows:

- NIST parametric approach to date is a key to understanding vulnerabilities.

- Use the NIST Dragon to compare to the SFM Standard; use the same configuration but compare results between the Class A Brand to the flying firebrands from the Dragon.

- Install the deck in a realistic configuration; attached to wall assembly since the NIST experiments can consider full scale assemblies.

- The exterior wall used in the experiments should be non-combustible; this way the test is specific to the decking material.

- Construct reentrant corner and install deck samples for testing in such a configuration; place a window on one of the walls and see if fire produced from burning deck (assuming that the deck ignites) can produce window breakage. 
- Regarding materials, the following suggestions were obtained:

o Consider Douglas Fir.

o Fire retardant treated wood not commonly used for decks; not recommend for NIST experimental campaign.

- Comments on the orientation of the deck boards:

0 The diagonal installation probably does not need to be tested.

o The standard installation is the same orientation as the SFM Standard.

o The opposed installation may create a different result particularly when evaluating the up-slope wind direction.

o Manufacturer's installation instructions do NOT specify orientation.

- Use manufacturer's instructions when spacing and installing the boards on the deck; deck installed is generally manufacturer specific.

- Typical deck installation will include a ledger board attached directly to the house:

o Ledger against exterior building wall without a gap (common construction practice)

o Ledger against exterior building wall with a gap (also common practice); may facilitate ember accumulation.

- When comparing the SFM Standard to the NIST Dragon experiments, use materials which passed the SFM Standard and use materials which failed the SFM Standard; this will help provide a relative comparison between the two test methods.

- Use CALFIRE's WUI Products Handbook to see which decking materials passed brand test.

- No consensus as to whether a railing should be used.

- Does the fact that a typical deck is located over a slope rather than a level surface make a difference in the results? Can the wind flow coming up-slope beneath the deck have a more significant impact on the ignition of the deck?

\subsection{Summary}

In WUI fires, decks have been observed to be an ignition vulnerability based on post-fire damage surveys. Current standard test methods do not simulate the dynamic process of multiple, wind driven firebrands bombarding decking assemblies. Before the development of the NIST Firebrand Generator (NIST Dragon) and the subsequent coupling of this device to the Fire Research Wind Tunnel Facility (FRWTF) at the Building Research Institute (BRI) in Japan, there were no experimental methods to actually generate wind firebrand showers in a controlled, laboratory setting to quantify these vulnerabilities [1-4].

Therefore, full scale tests are planned to quantify the vulnerabilities of decking assemblies to firebrand showers using the NIST Dragon coupled to BRI's FRWTF. Decks have been observed to be an ignition vulnerability based on post-fire damage surveys. This publication summarizes the results obtained from a workshop that was held in June, 2011 by NIST to provide input on the type of decking assemblies commonly found as well as the type of configuration that may be useful to expose to wind driven firebrand showers. The focus has been placed on the state of California since many large WUI fires have occurred there over the past 10 years [13]. These findings will be considered as NIST develops their experimental plans. The results of the full 
scale tests will be reported and may serve as the basis for developing reduced scale test methods for decking assemblies as well as providing the scientific basis for building code change. 


\section{References}

[1] S.L. Manzello, J.R. Shields, J.C. Yang, Y. Hayashi, D. Nii, On the Use of a Firebrand Generator to Investigate the Ignition of Structures in WUI Fires, In Proceedings of the 11th International Conference on Fire Science and Engineering (INTERFLAM), Interscience Communications, London, (2007) pp. 861-872.

[2] S.L. Manzello, et al., On the Development and Characterization of a Firebrand Generator, Fire Safety Journal, 43: 258-268, 2008.

[3] S.L. Manzello, Y. Hayashi, T. Yoneki, Y. Yamamoto, Quantifying the Vulnerabilities of Ceramic Tile Roofing Assemblies to Ignition during a Firebrand Attack, Fire Safety Journal, 45:35-43, 2010.

[4] S.L. Manzello, S.H. Park, J.R. Shields, Y. Hayashi, S. Suzuki, Comparison Testing Protocol for Firebrand Penetration Through Building Vents: Summary of BRI/NIST Full Scale and NIST Reduced Scale Results, NIST TN 1659, January 2010.

[5] S.L. Manzello and S. Suzuki, Summary of Workshop on Research Needs for Full Scale Testing to Determine Vulnerabilities of Siding Treatments and Glazing Assemblies to Ignition by Firebrand Showers, NIST Special Publication 1111, 2010.

[6] S.L. Manzello, S. Suzuki, Y. Hayashi, Exposing Siding Treatments and Walls Fitted with Eaves to Wind-Driven Firebrand Showers, Fire and Materials Conference, San Francisco, CA, February, 2011.

[7] S.L. Manzello, S. Suzuki, and Y. Hayashi, Exposing Glazing Assemblies to Firebrand Showers, Japan Association for Fire Science and Engineering, Tokyo, Japan, May, 2011.

[8] S.L. Manzello, Quantify Structure Vulnerabilities to Ignition from Firebrand Showers, ASTM E05 Research Review, Anaheim, CA, June 13, 2011.

[9] California Building Standards Commission Website (http://www.bsc.ca.gov/default.htm).

[10] ASTM E108 Standard Test Methods for Fire Tests of Roof Coverings, ASTM International, West Conshohocken, PA, 2003.

[11] E.I.D. Foote, J. Liu, and S.L. Manzello, Characterizing Firebrand Exposure During Wildland-Urban Interface (WUI) Fires, Fire and Materials Conference, San Francisco, CA, 2011.

[12] A. Maranghides, W.E. Mell, A Case Study of A Community Affected by the Witch and Guejito Fires, NIST TN 1635, April, 2009.

[13] W.E. Mell, S.L. Manzello, A. Maranghides, B. Butry, and R. Rehm, Wildland-Urban Interface Fires: Overview and Research Needs, Int'l J. Wildland Fire, 19: 238-251, 2010. 


\section{Acknowledgements}

Mr. Ruben Grijalva, former State Fire Marshal and former CALIFRE director gave a presentation on overview of WUI problem in California and moderated this workshop. His excellent help is really appreciated. Mr. Stuart Tom, C.B.O, served as the official note taker and Mr. Neville Pereira, LA Basin Chapter President, arranged the venue and location. Their great help is really appreciated. The valuable input of all participants is warmly appreciated. The Science and Technology Directorate of the U.S. Department of Homeland Security sponsored the production of this material under Interagency Agreement IAA HSHQDZ-10-X-00288 with the National Institute of Standards and Technology (NIST). 


\section{Appendix 1}

\section{Attendance List}

\begin{tabular}{|c|c|c|}
\hline No. & Name (Alphabetical by last name) & Organization \\
\hline 1 & Brent Berkompas & Fire Vent Safety Association \\
\hline 2 & Laura Blaul & Orange County Fire Authority \\
\hline 3 & Tom Christopher & Laguna Beach Fire Department \\
\hline 4 & Tom Czlapinski & California Redwood Association \\
\hline 5 & Chris Dicus & California Polytechnic University at San Luis Obispo \\
\hline 6 & Ken Dunham & Lumber Association of California and Nevada \\
\hline 7 & Tom Fabian & Underwriters Laboratories (UL) \\
\hline 8 & Ethan Foote & $\begin{array}{l}\text { CALFIRE (unable to attend, reviewed presentations and } \\
\text { provided post-workshop input) }\end{array}$ \\
\hline 9 & Scott Franklin & Scott Franklin Consultants \\
\hline 10 & Chris Freeman & Ganahl Lumber Company \\
\hline 11 & Rich Geary & Hoover Treated Wood Products \\
\hline 12 & Ruben Grijalva & $\begin{array}{l}\text { Former California State Fire Marshall; Former } \\
\text { CALFIRE Director }\end{array}$ \\
\hline 13 & Chip Herr & Timber Tech \\
\hline 14 & Bill Hendricks & Safer Building Solutions \\
\hline 15 & Tim Hummel & California Timberline, Inc. \\
\hline 16 & Joe Lozano & Boise Cascade \\
\hline 17 & Ian MacDonald & $\begin{array}{l}\text { Southern California Fire Prevention } \\
\text { Officers/CALCHIEFS }\end{array}$ \\
\hline 18 & Samuel Manzello & NIST \\
\hline 19 & Rodney McPhee & Canadian Wood Council \\
\hline 20 & Pete Melchtry & Ganahl Lumber Company \\
\hline 21 & Don Oaks & $\begin{array}{l}\text { Southern California Fire Prevention } \\
\text { Officers/CALCHIEFS }\end{array}$ \\
\hline 22 & Mark Pawlicki & Sierra Pacific Industries \\
\hline 23 & Neville Pereira & LA Basin ICC Chapter President \\
\hline 24 & Steve Quarles & IBHS/University of California Cooperative Extension \\
\hline 25 & Alan Schall & Azek \\
\hline 26 & Kevin Scott & International Code Council (ICC) \\
\hline 27 & Kuma Sumathipala & American Wood Council \\
\hline 28 & Stuart Tom & City of Glendale, California \\
\hline 29 & Jon Traw & ASTM E05.14.08 - WUI Exposures Chairman \\
\hline 30 & Steven Winkel & The Preview Group \\
\hline
\end{tabular}


Appendix 2

Presentations delivered in workshop 


\title{
Introduction \\ Past, Present \& Future
}

\author{
Ruben Grijalva
}

Former State Fire Marshal

Former CAL FIRE Director
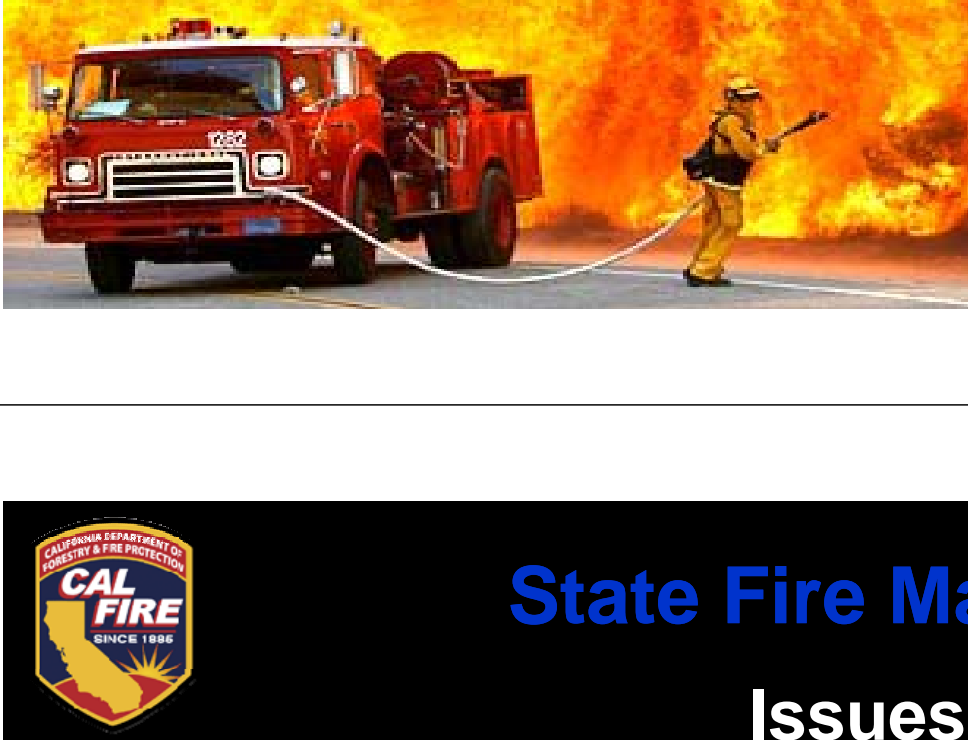

\section{State Fire Marshal}

Issues

State Building Standards and ICC

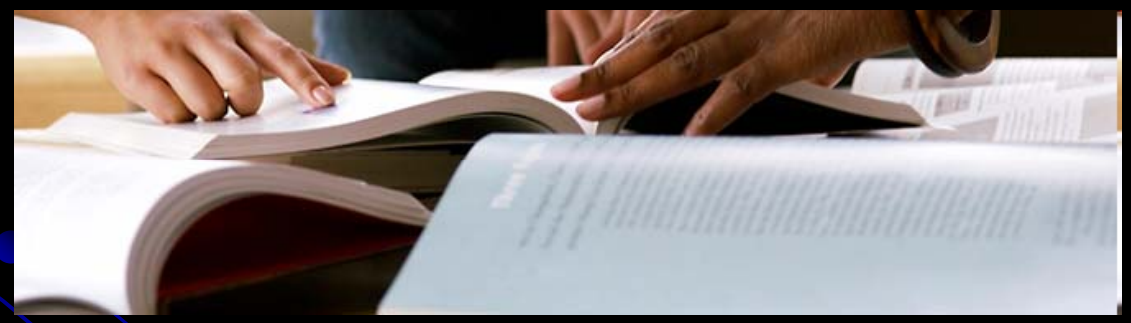




\section{State Fire Marshal}

\section{Issues}

\section{Wildland Urban Interface Building Standards}

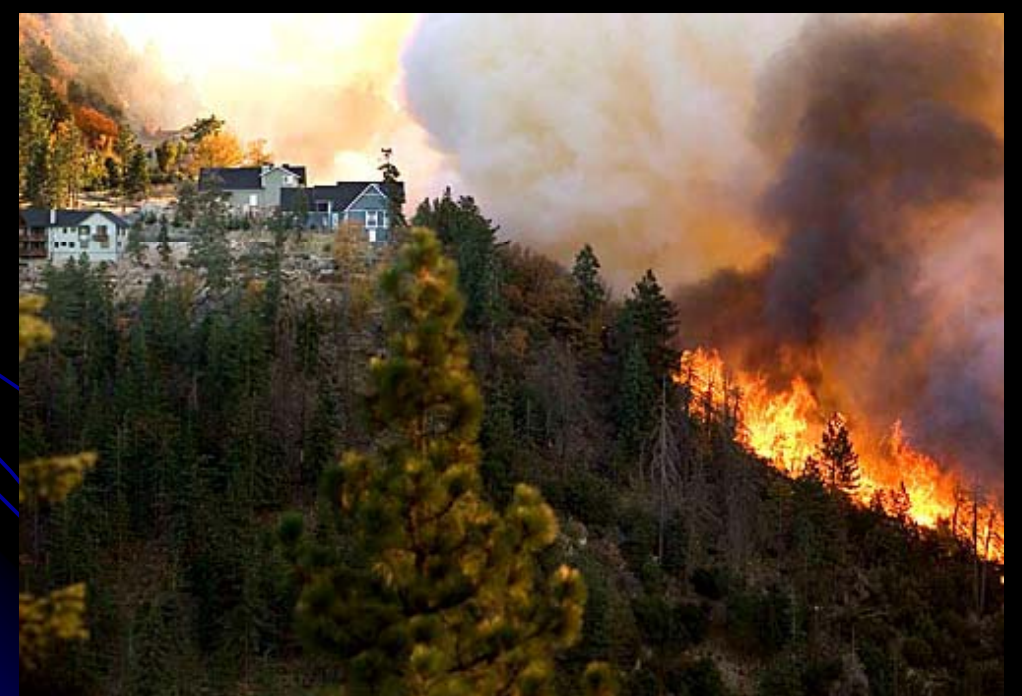

Direct Protection Area

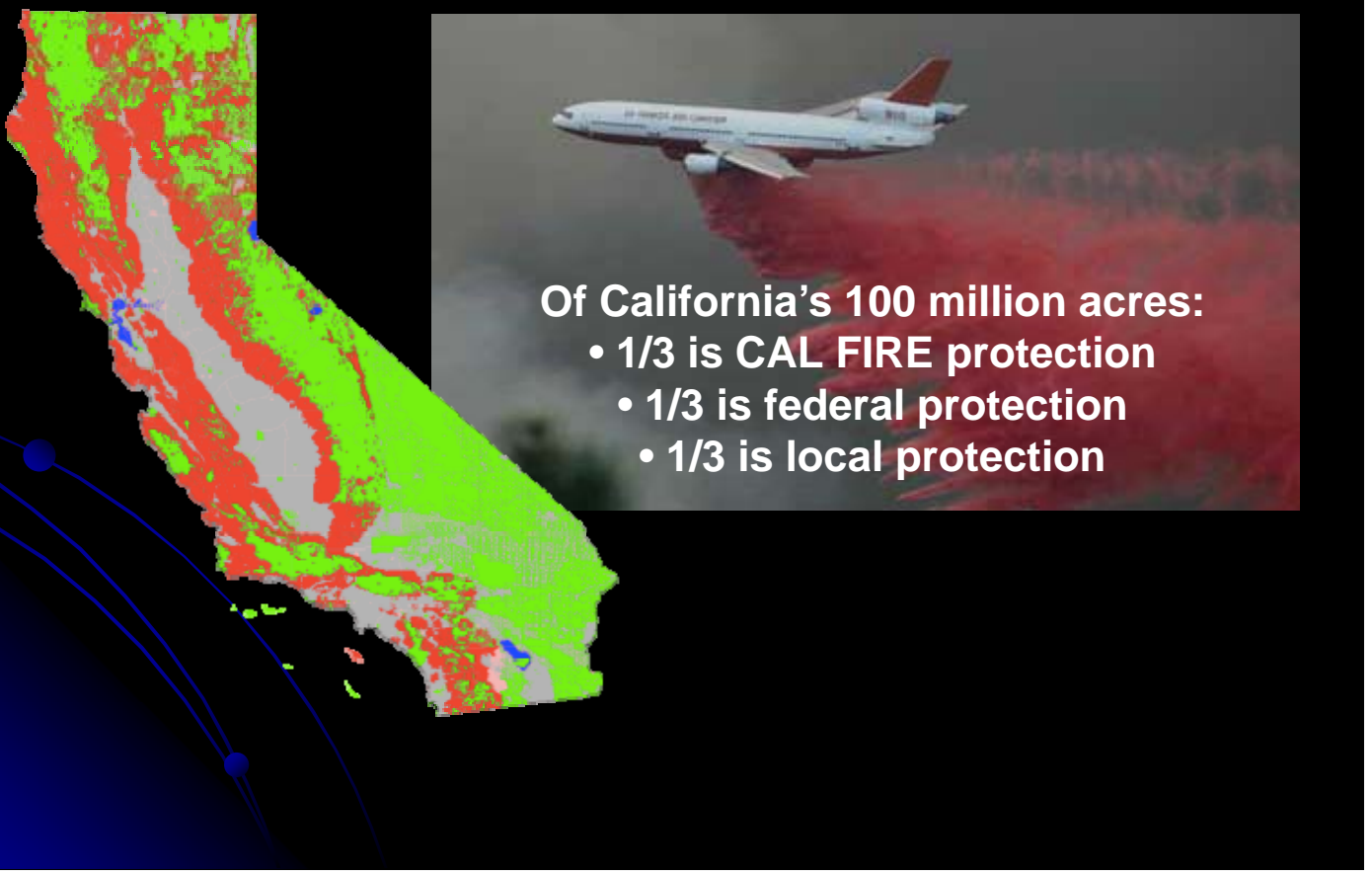


Initial Attack Philosophy

\section{Fire Protection Objective: Suppress 95\% of all wildfires to 10 acres or less}

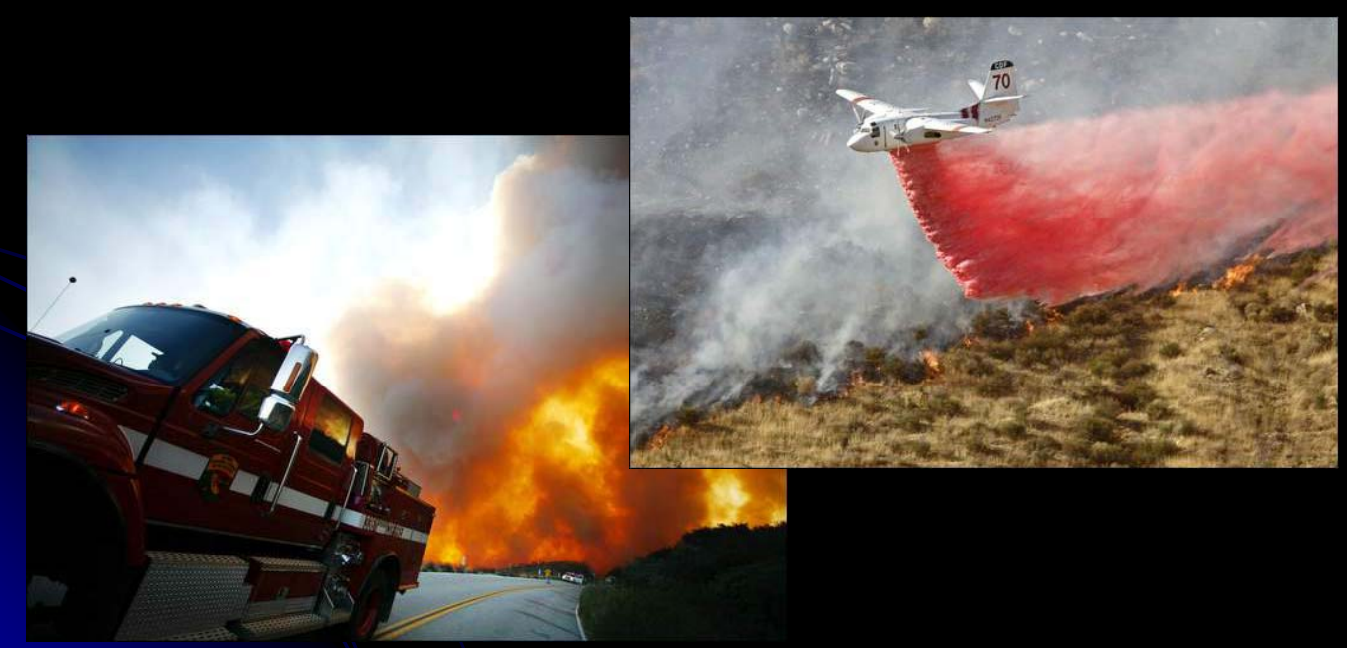

Governor's Executive Order

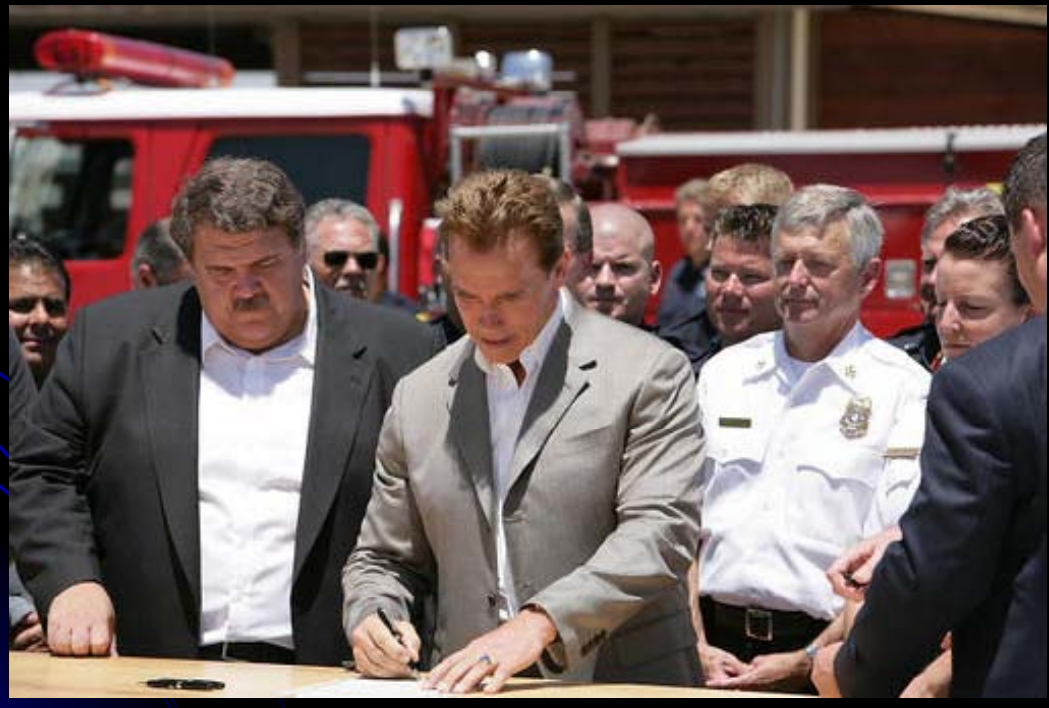




\section{Fire Siege}

Pre-Season Preparation

700 More Firefighters

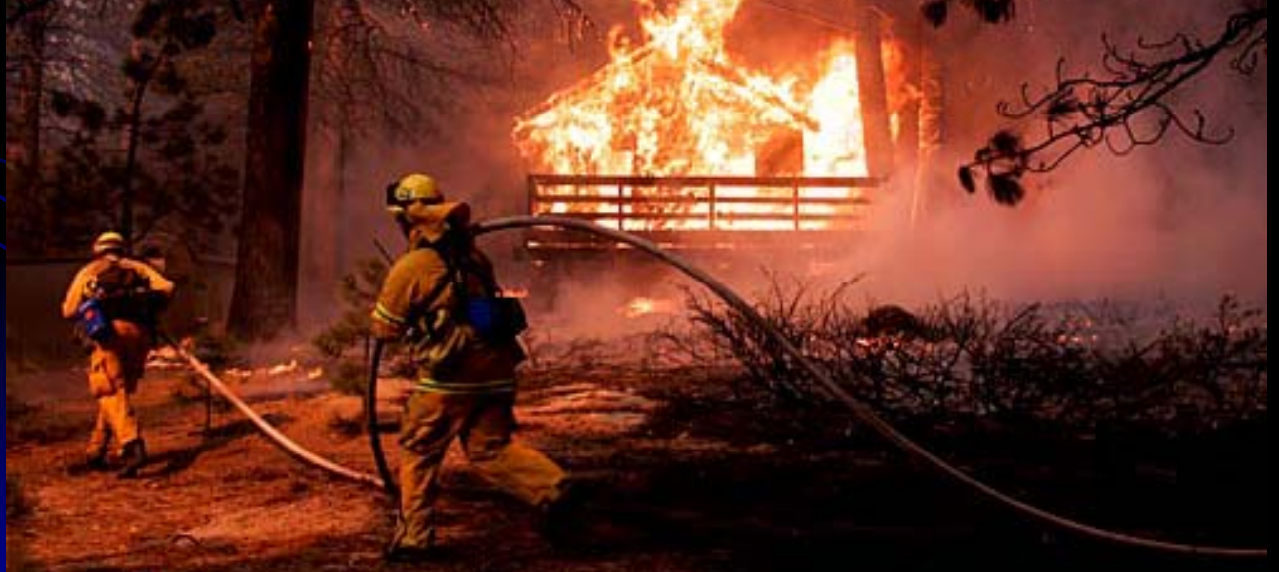

Pre-Season Preparation

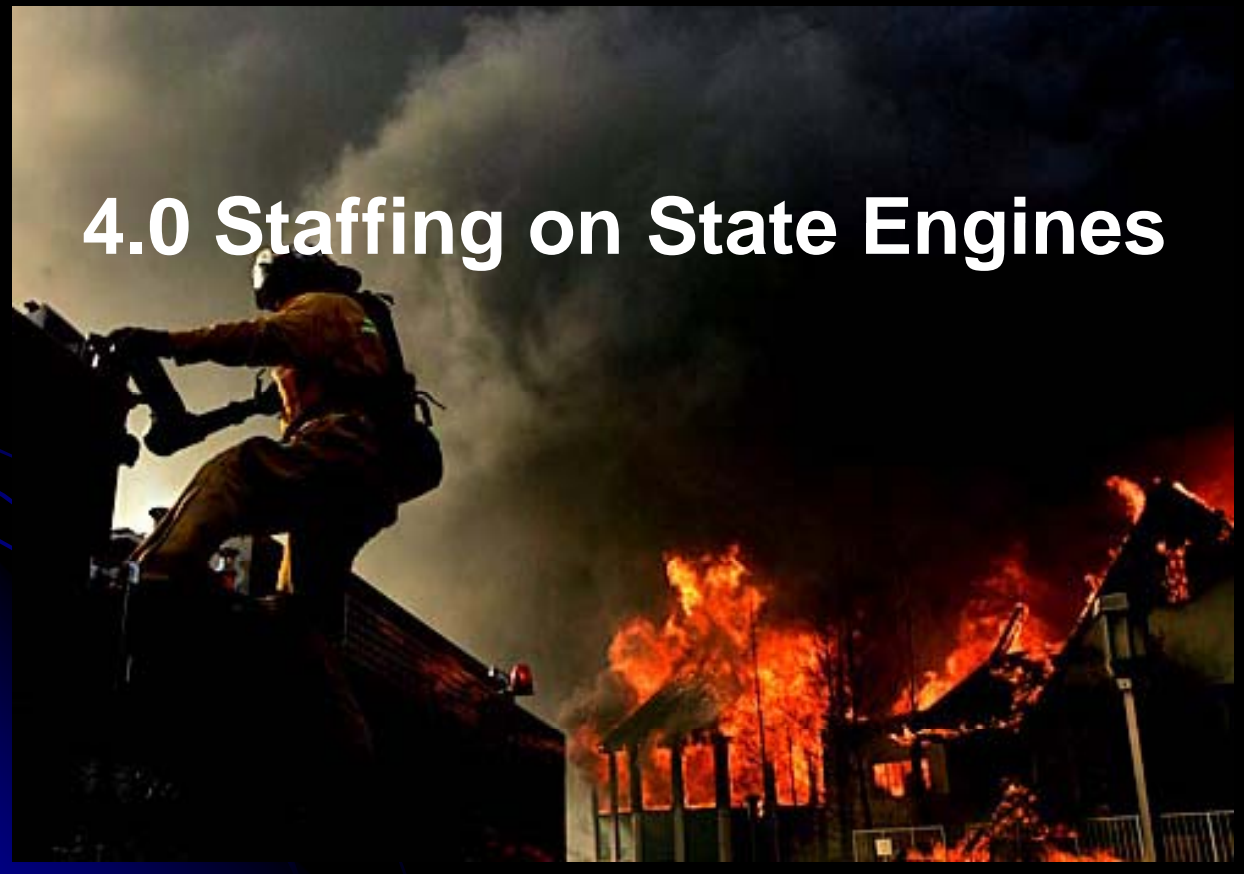




\section{Pre-Season Preparation}

\section{Defensible Space Inspectors}

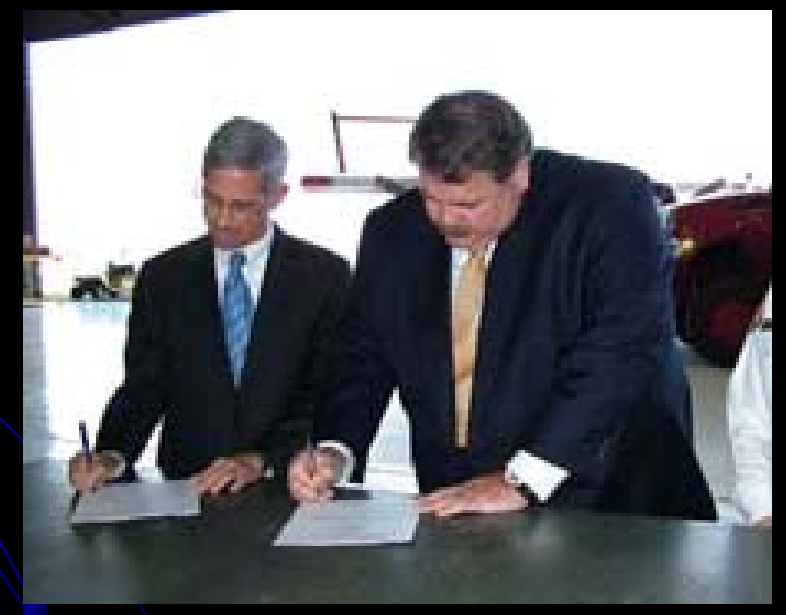

Pre-Season Preparation

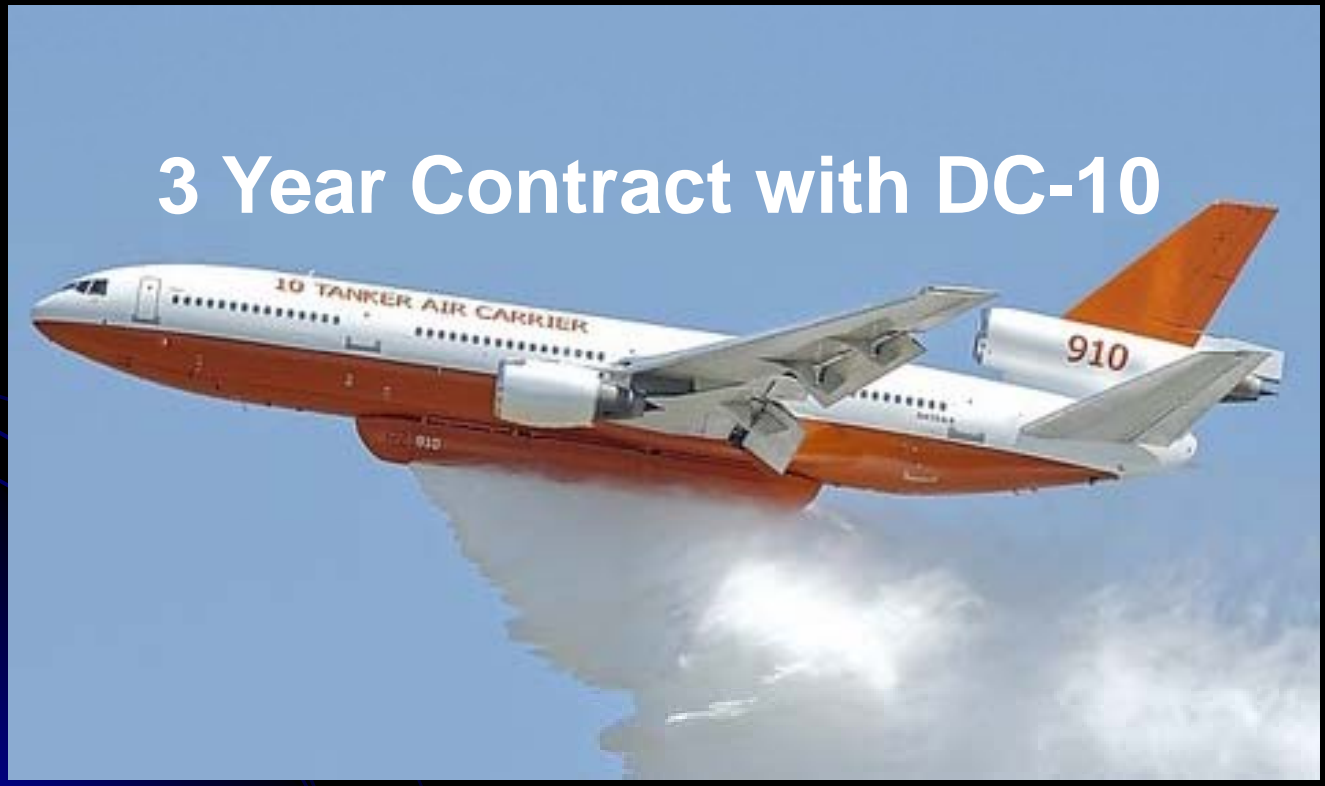




\section{Fire Siege \\ Pre-Season Preparation}

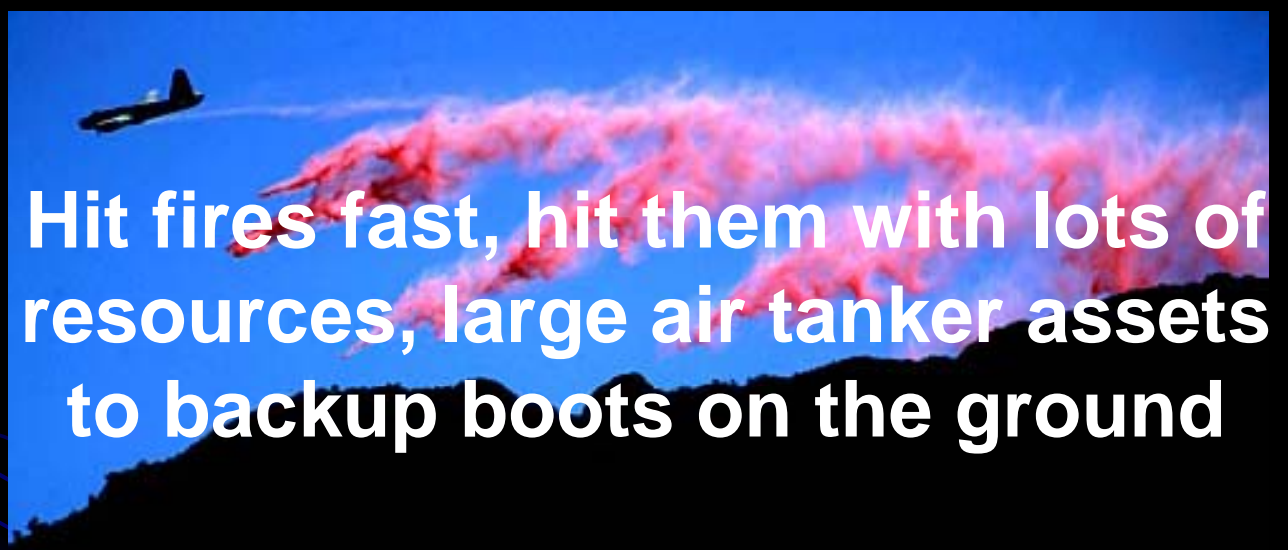

Northern Region

21 Units

6 Contract Counties

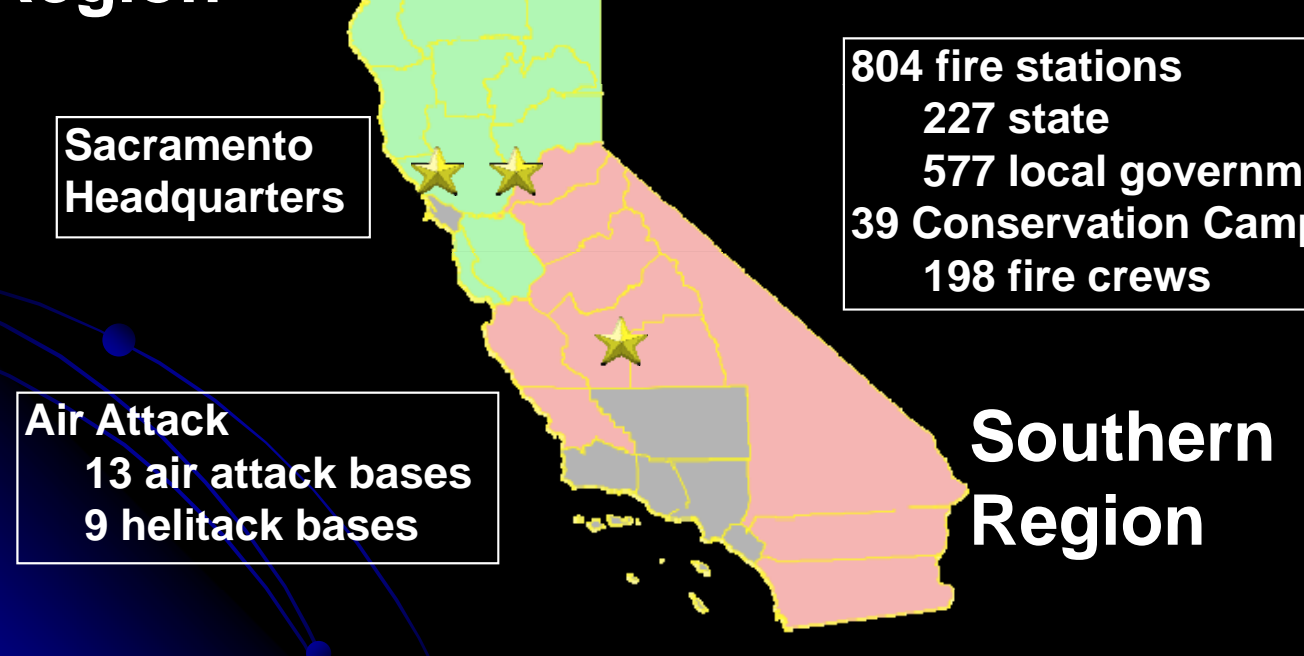




\section{Fire Siege \\ Conditions}

- CA has various micro climates

- Santa Ana Wind Event

- Sustained wind speeds - 40-60 MPH

- Wind gusts - up to $100 \mathrm{MPH}$

- Fuel moistures drop to single digits - 9\%-12\%

- Dead and dying trees and brush from freeze, disease, and infestation

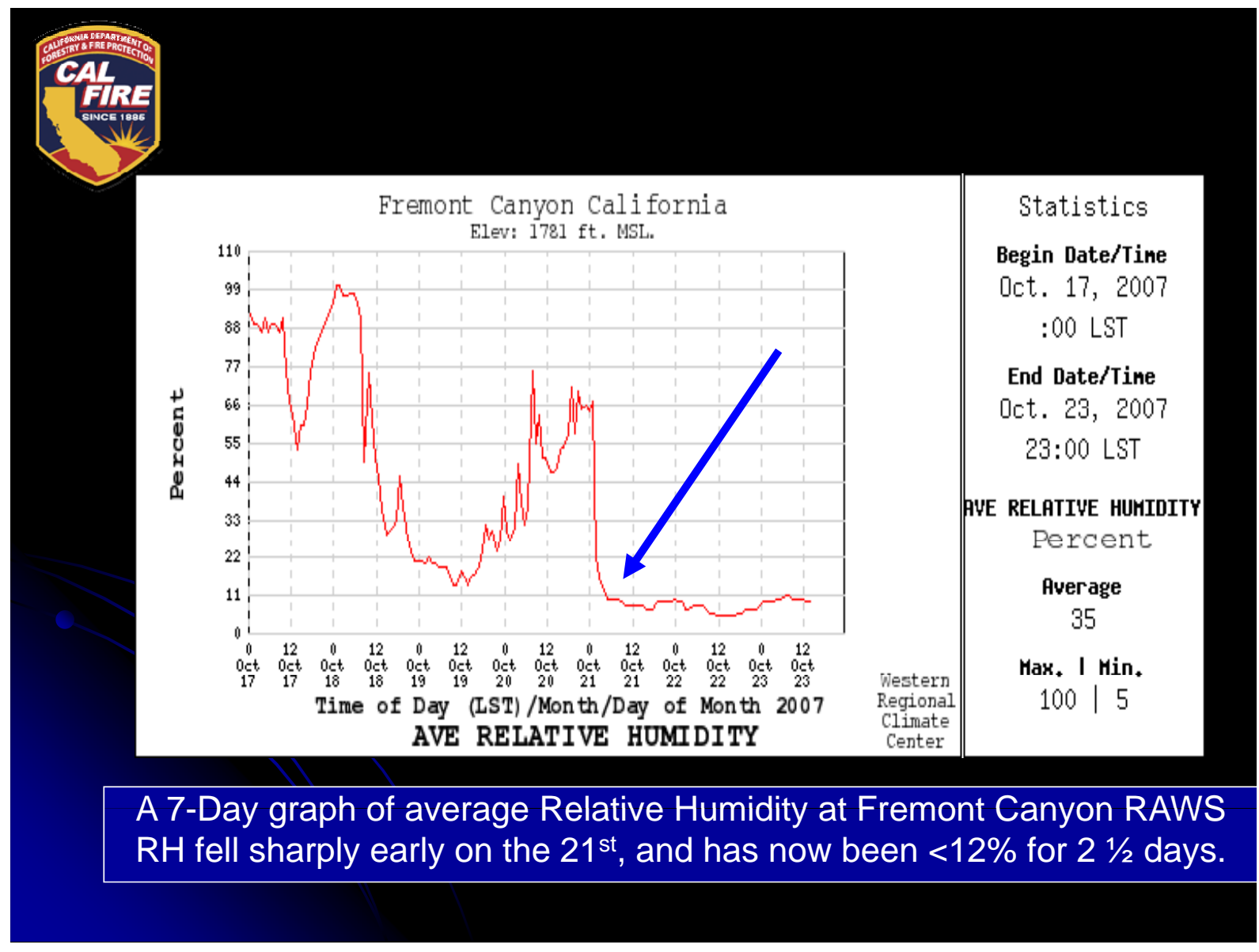



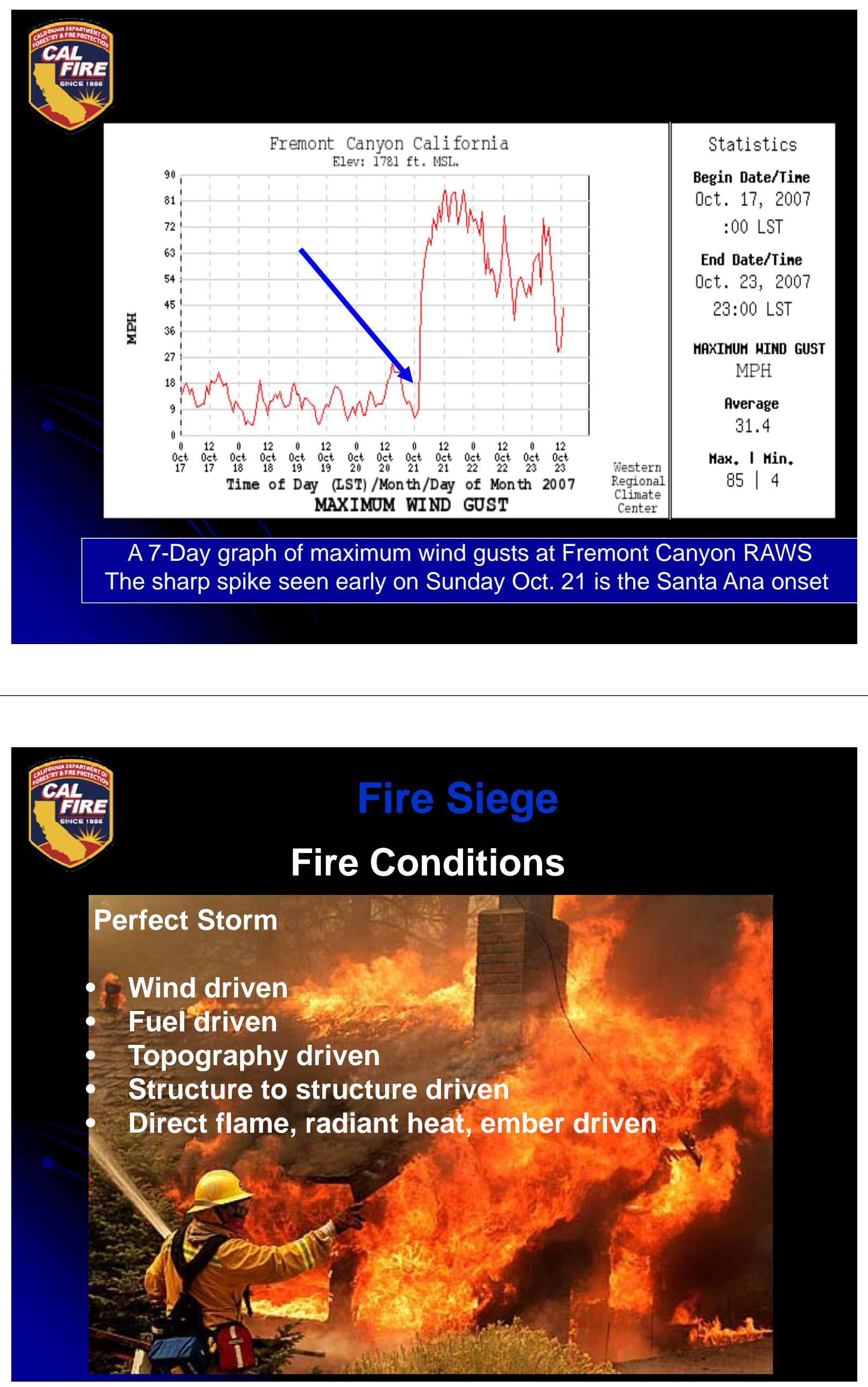

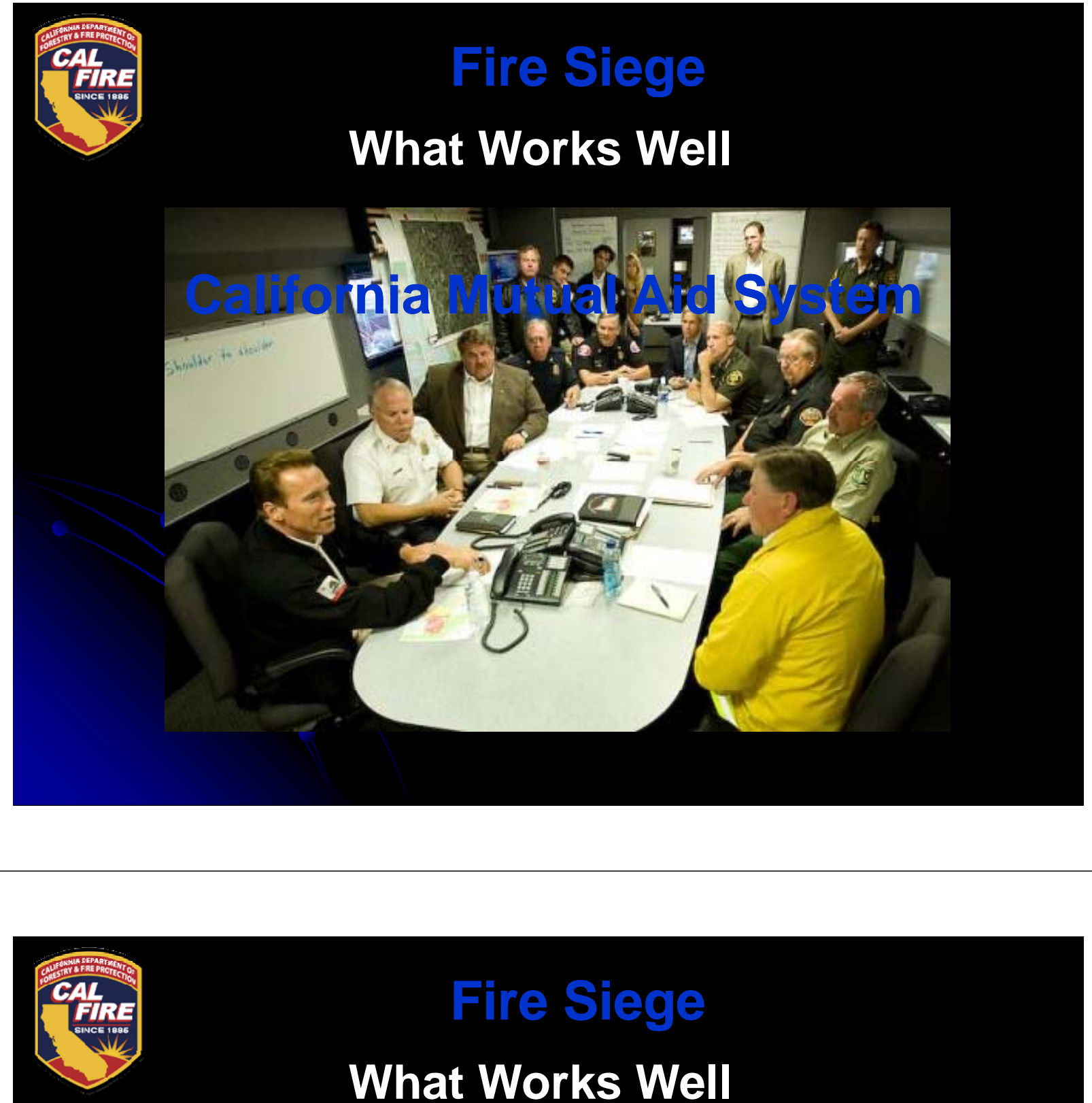

\section{Fire Siege \\ What Works Well}

Mobilize a massive amount of personnel in a condensed period

\section{of time.}




\section{What Worked Well}

\section{Multi-State Response. The number of different fire departments involved approx. \\ 1,148 .}

\section{october vite stege 2007}

What Worked Well

Total firefighters: 15,616

Engines: 2,585

Strike Teams/Task Forces: 263

Dozers: 225

Handcrews: 298

Watertenders: 284

Overhead personnel: 1,707 


\section{Fire siege}

Lessons Learned

\section{Need for Better Land Use I Planning / Prevention}

Need for more local resources I staffing / surge capacity 


\section{Fire Siege \\ Lessons Learned}

Need for streamlined resource re-deployment system

\section{Fire Siege}

\section{Preventing the Next Firestorm}

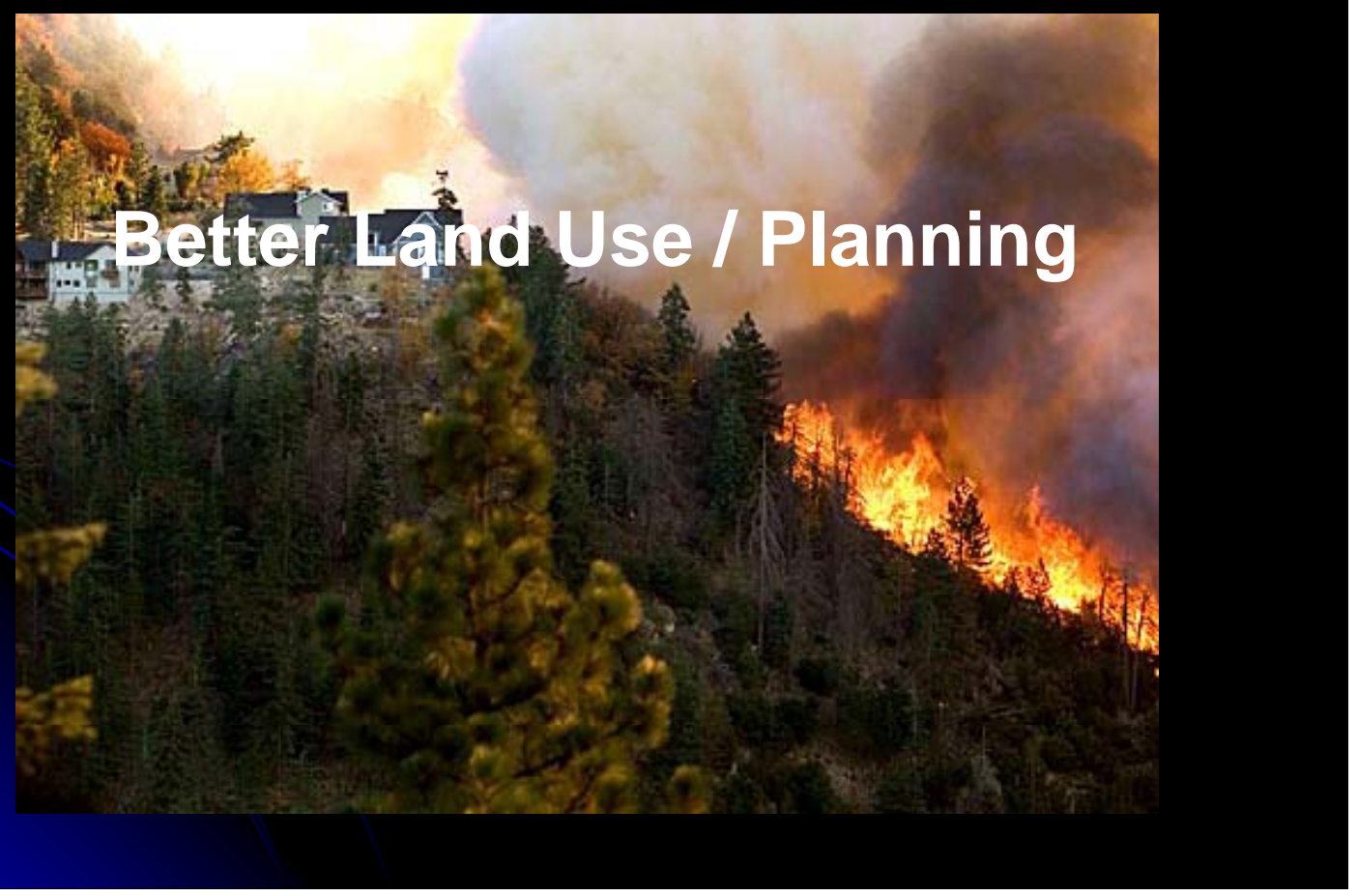




\section{중}

\section{Fire Siege}

\section{Preventing the Next Firestorm}

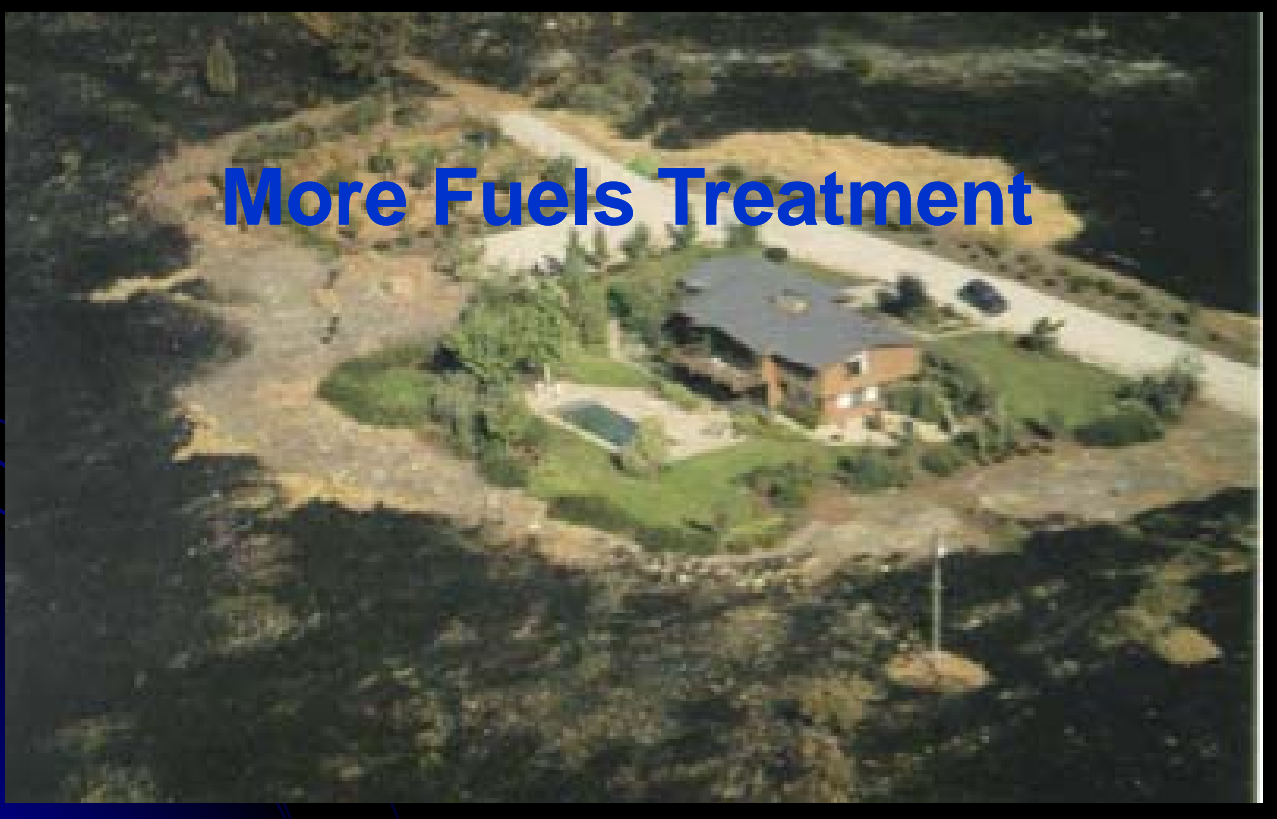

\section{Fire Siege}

Preventing the Next Firestorm

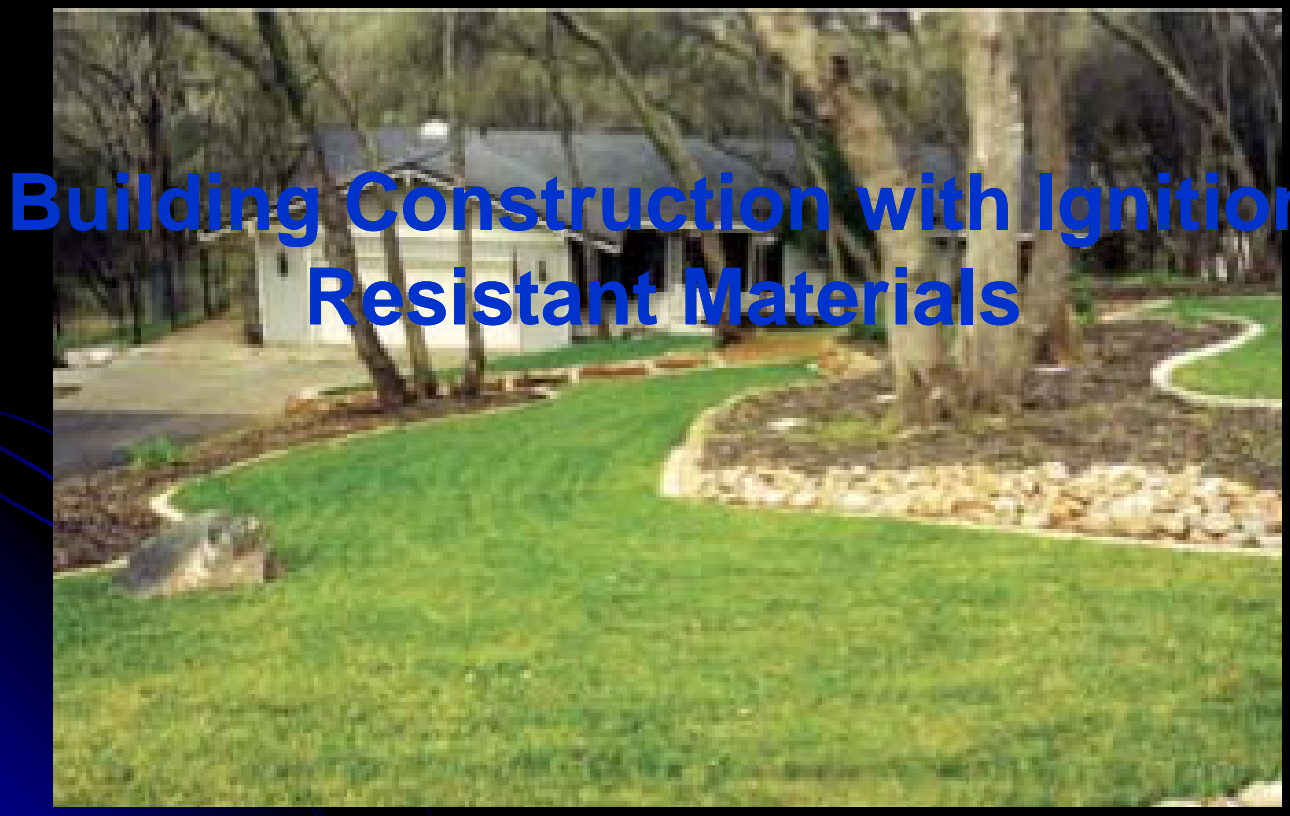




\section{장}

\section{Fire Siege}

\section{Preventing the Next Firestorm}

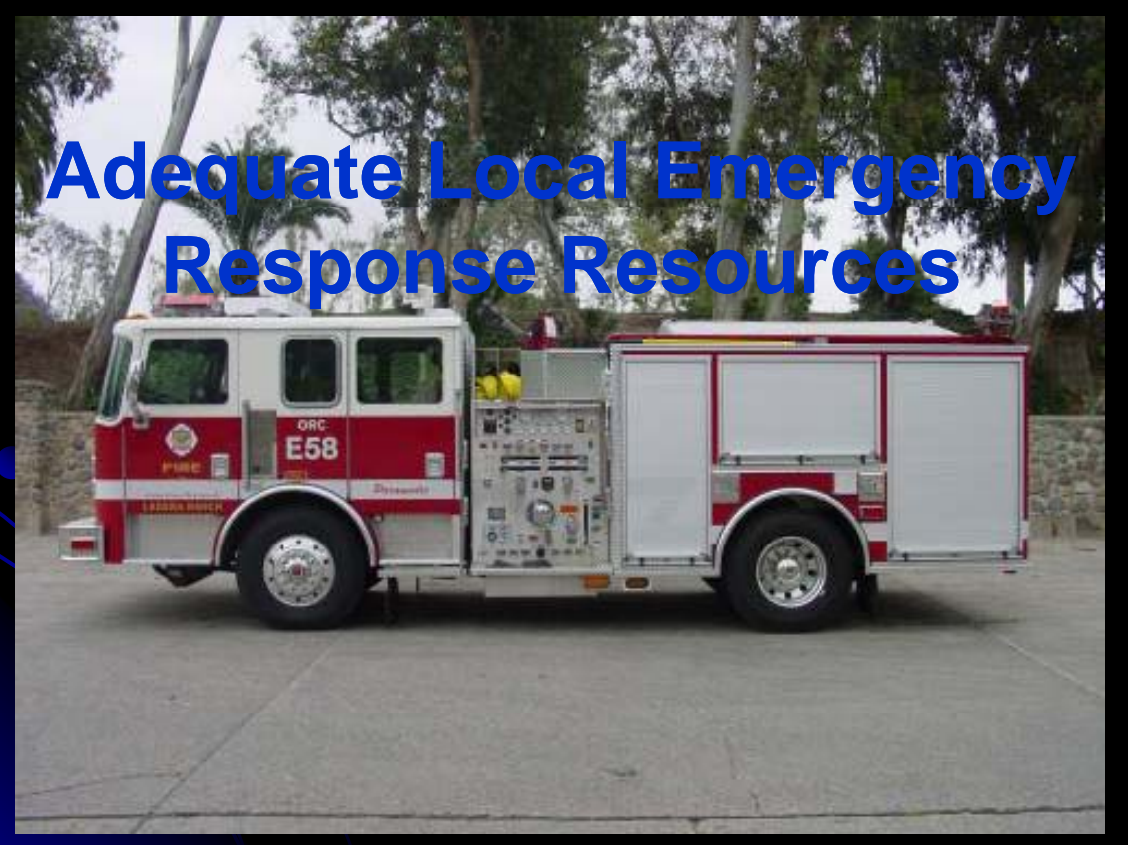

\section{Fire Siege}

\section{Preventing the Next Firestorm}

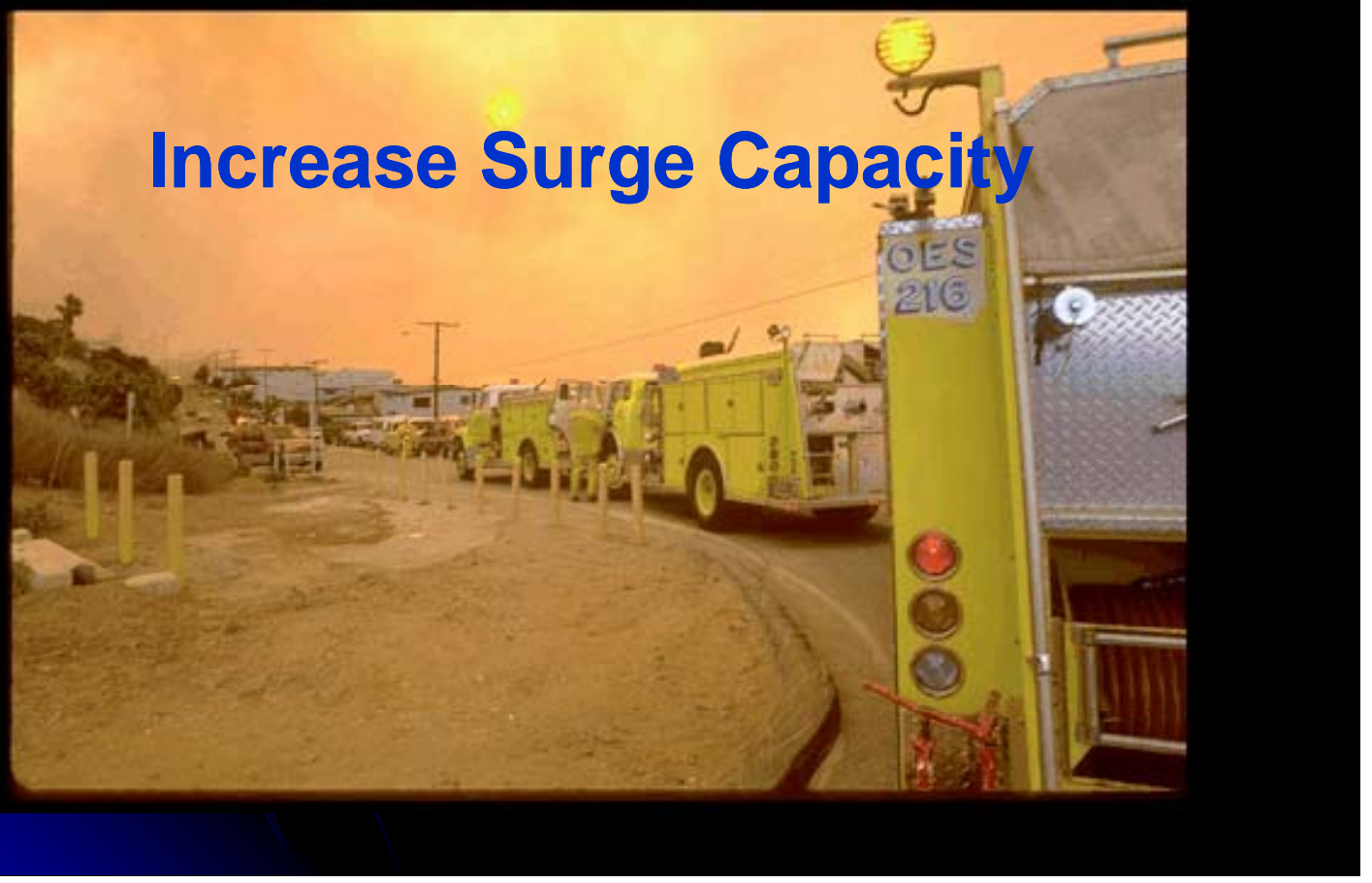




\section{Fire Siege}

\section{Preventing the Next Firestorm}

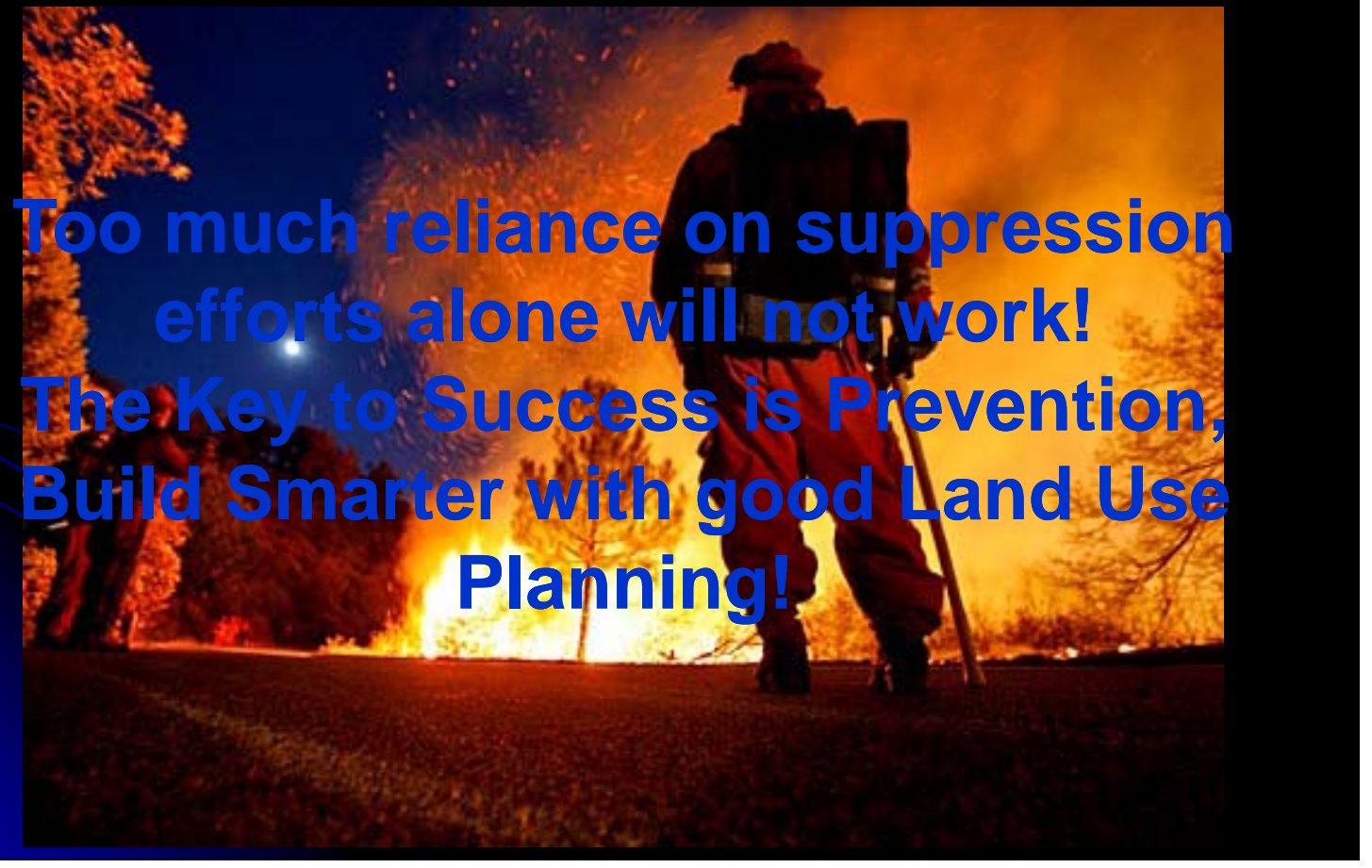




\title{
Quantifying Structure Vulnerabilities to Ignition from Firebrand Showers
}

\author{
Dr. Samuel L. Manzello \\ Mechanical Engineer \\ Fire Measurements Group \\ Engineering Laboratory (EL) \\ National Institute of Standards and Technology (NIST) \\ Gaithersburg, MD 20899-8662 USA \\ samuelm@nist.gov; +1-301-975-6891 (office)

\section{Decking Workshop} \\ June $15^{\text {th }}, 2011$ \\ National Institute of Standards and Technology

NGT

\section{Special Thanks}

- Dr. Sayaka Suzuki (NIST)

- Dr. Yoshihiko Hayashi (BRI)

- Mr. Ruben Grijalva

- Mr. Stuart Tom

- Mr. Neville Pereira
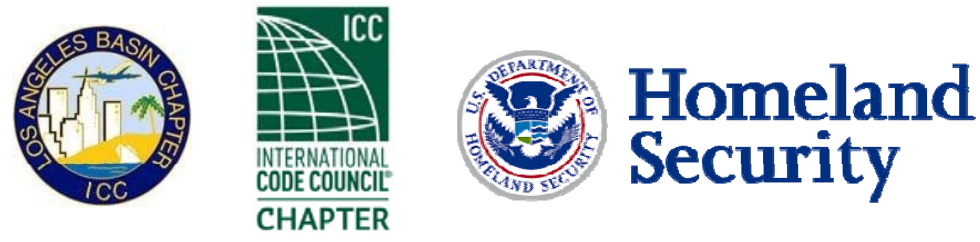


\section{Wildland-Urban Interface (WUI) Fires}

WUI - structures and wildland vegetation coexist

Of the 10 largest fire loss incidents (> \$1B) in U.S. history, 5 were WUI fires - all within the last 17 years

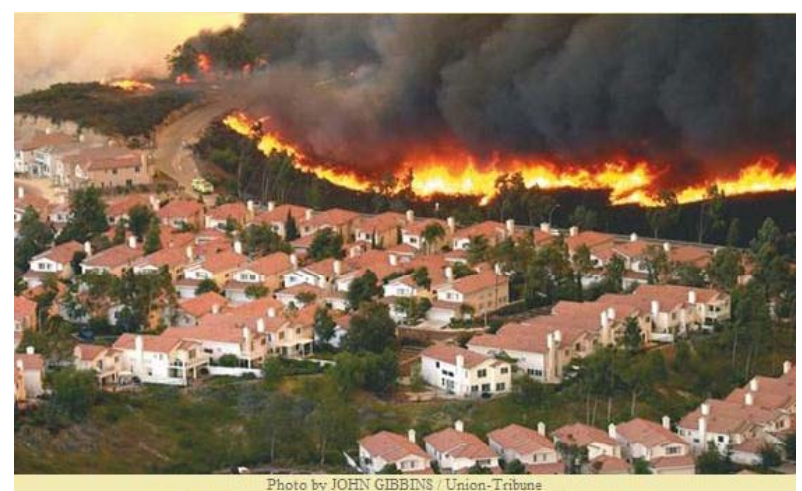

Cedar Fire about to engulf the Scripps Ranch residential community

Proven risk assessment and mitigation tools are needed NIST

National Institute of Standards and Technology

\section{Structure Ignition in Urban and WUI Fires}

- Firebrands major cause of ignition

- Understanding firebrand ignition of structures important to mitigate fire spread Australia/Japan/USA

Objective: Investigate ignition of structures to firebrand showers 


\section{Partnerships}

- BRI - Japan

- US Department of Homeland Security

\section{Customers}

- CALFIRE

- ASTM (Manzello voting member)

- ASTM E05.14 External Fires
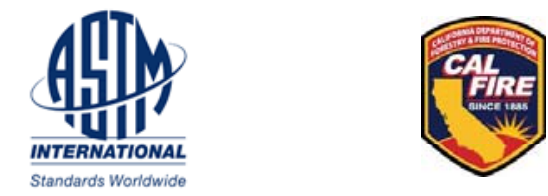

- Results useful for:

NLST- ASTM, CALFIRE, ICC, NFPA, ISO, Insurance Industry, Homeowners

\section{International Collaboration BRI (Japan) and BFRL-NIST (USA)}

- Firebrands: generation, transport, ignition

- Research focused on how far firebrands travel for $\mathbf{4 0}$ yrs!!

- Nice Academic Problem - Not helpful to design structures

- Vulnerable points where firebrands may enter structure - Unknown/guessed!

- Difficult to replicate firebrand attack!

- Entirely new experimental methods needed! Goals

Science - Building Codes/Standards; Retrofit construction Design structures to be more resistant to firebrand ignition 


\section{Building Research Institute (BRI)}

- Fire Research Wind Tunnel Facility (FRWTF)

- Unique facility - investigate influence of wind on fire

- Constructed more than 10 years before IBHS wind tunnel
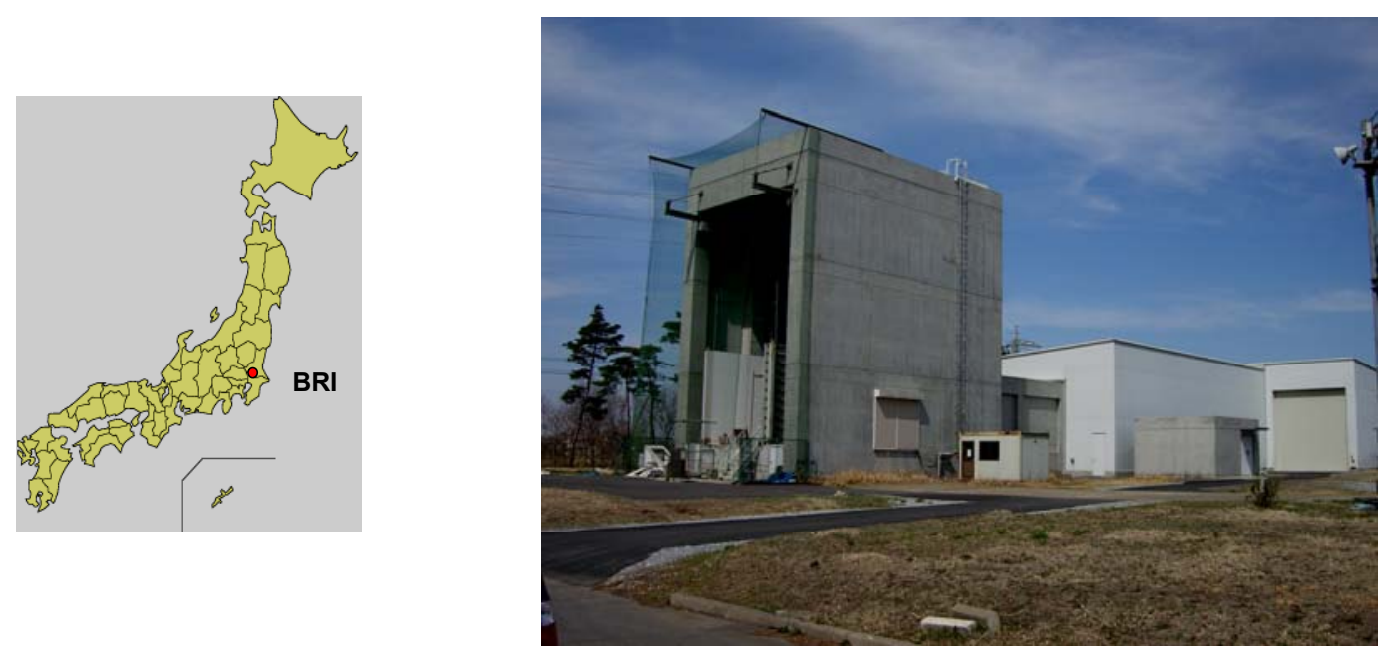

Fire Research Wind Tunnel Facility

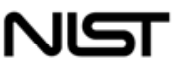

(FRWTF)

\section{NIST Dragon 龍}

\section{First Generation Device}

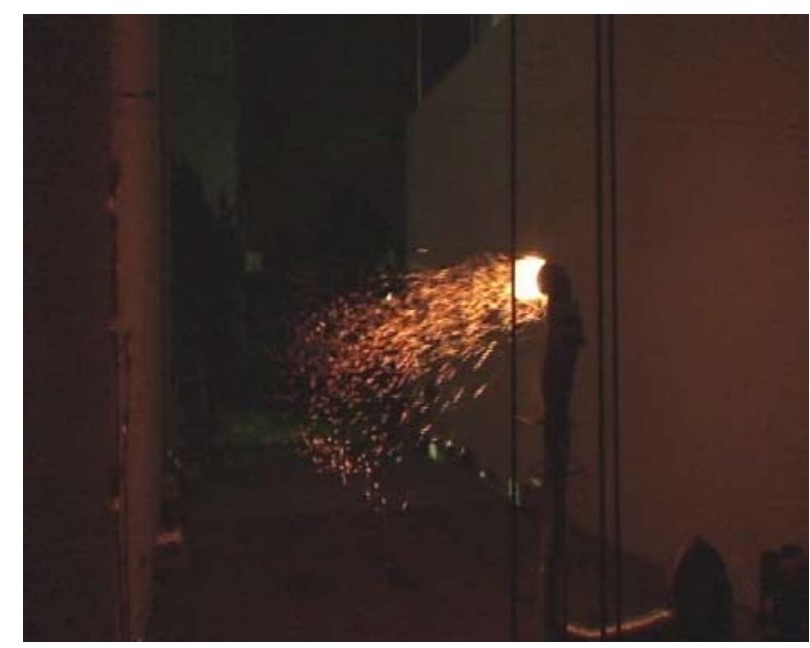

Firebrand size/mass commensurate to full scale tree burns and actual WUI fire (2007 Angora Fire) 


\section{Roofing Studies}

\section{NLT}

\section{Current Roofing Standards}

Japan/USA

Use This Test!

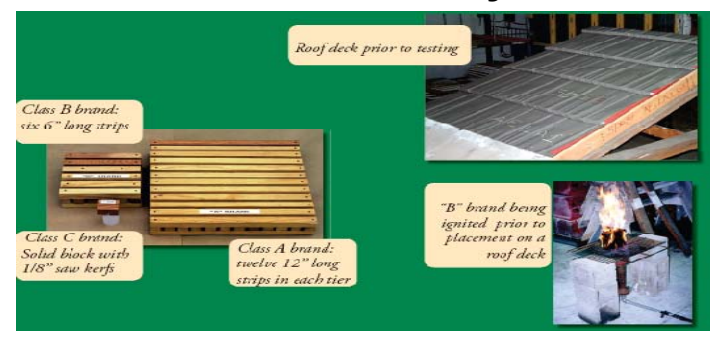

Does not simulate dynamic firebrand attack!

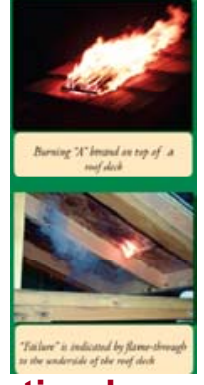

$12 \mathrm{mi} / \mathrm{hr}$

$(5.3 \mathrm{~m} / \mathrm{s})$

Mitchell \&Patashnik [2007 ] - possible correlation homes ignited in 2003 Cedar Fire with those homes fitted with ceramic tile roofing
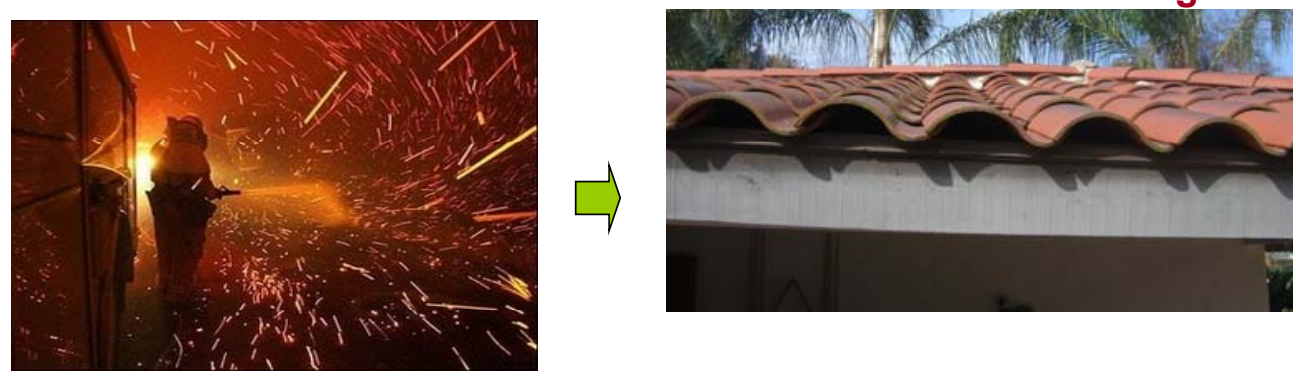


\section{Ceramic Roofing}

Aged Roofing Simulated: OSB, then tiles (no tar paper)
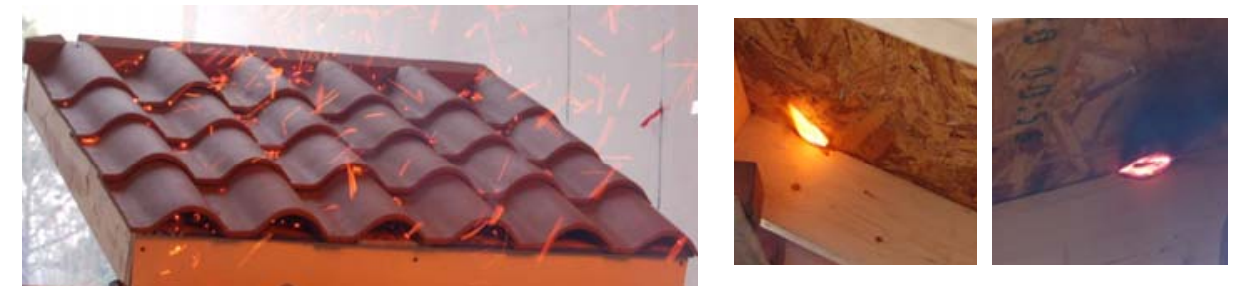

\begin{tabular}{|c|c|c|c|c|}
\hline $\mathrm{U}_{\infty}(\mathrm{m} / \mathrm{s})$ & $\begin{array}{c}\text { OSB/TP/CT } \\
\text { No Bird Stops }\end{array}$ & $\begin{array}{c}\text { OSB/TP/CT } \\
\text { With Bird } \\
\text { Stops }\end{array}$ & $\begin{array}{c}\text { OSB/CT } \\
\text { No Bird Stops }\end{array}$ & $\begin{array}{c}\text { OSB/CT } \\
\text { With Bird } \\
\text { Stops }\end{array}$ \\
\hline 7 & SI & NI & SI to FI & SI \\
\hline 9 & SI & NI & SI to FI & SI \\
\hline
\end{tabular}

New Roofing Construction: OSB, Tar Paper, then Ceramic Tiles

\section{NLT}

\section{Ceramic Roofing}

Aged Roofing Simulated: OSB, then tiles (no tar paper)

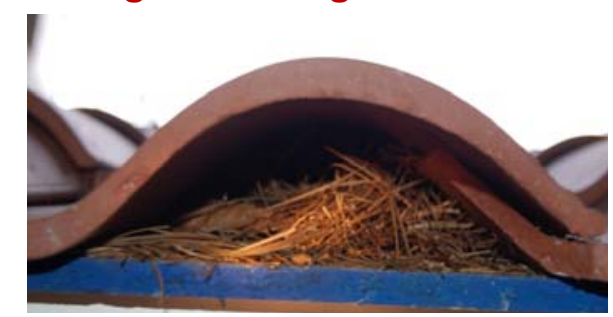

\begin{tabular}{|c|c|c|c|c|}
\hline $\mathrm{U}_{\infty}(\mathrm{m} / \mathrm{s})$ & $\begin{array}{c}\text { OSB/TP/CT } \\
\text { No Bird Stops }\end{array}$ & $\begin{array}{c}\text { OSB/TP/CT } \\
\text { With Bird } \\
\text { Stops }\end{array}$ & $\begin{array}{c}\text { OSB/CT } \\
\text { No Bird Stops }\end{array}$ & $\begin{array}{c}\text { OSB/CT } \\
\text { With Bird } \\
\text { Stops }\end{array}$ \\
\hline 7 & SI & SI & SI to FI & SI \\
\hline 9 & SI & SI & SI to FI & SI \\
\hline
\end{tabular}

New Roofing Construction: OSB, Tar Paper, then Ceramic Tiles

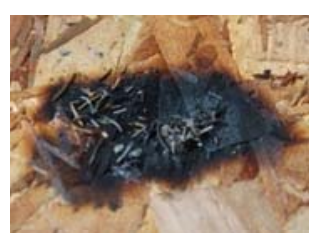




\section{Detailed Investigation of Firebrand Penetration through Building Vents}

\section{NLT}

National Institute of Standards and Technology

\section{Firebrand Penetration Through Vents}

\section{Experiments conducted in 2007}

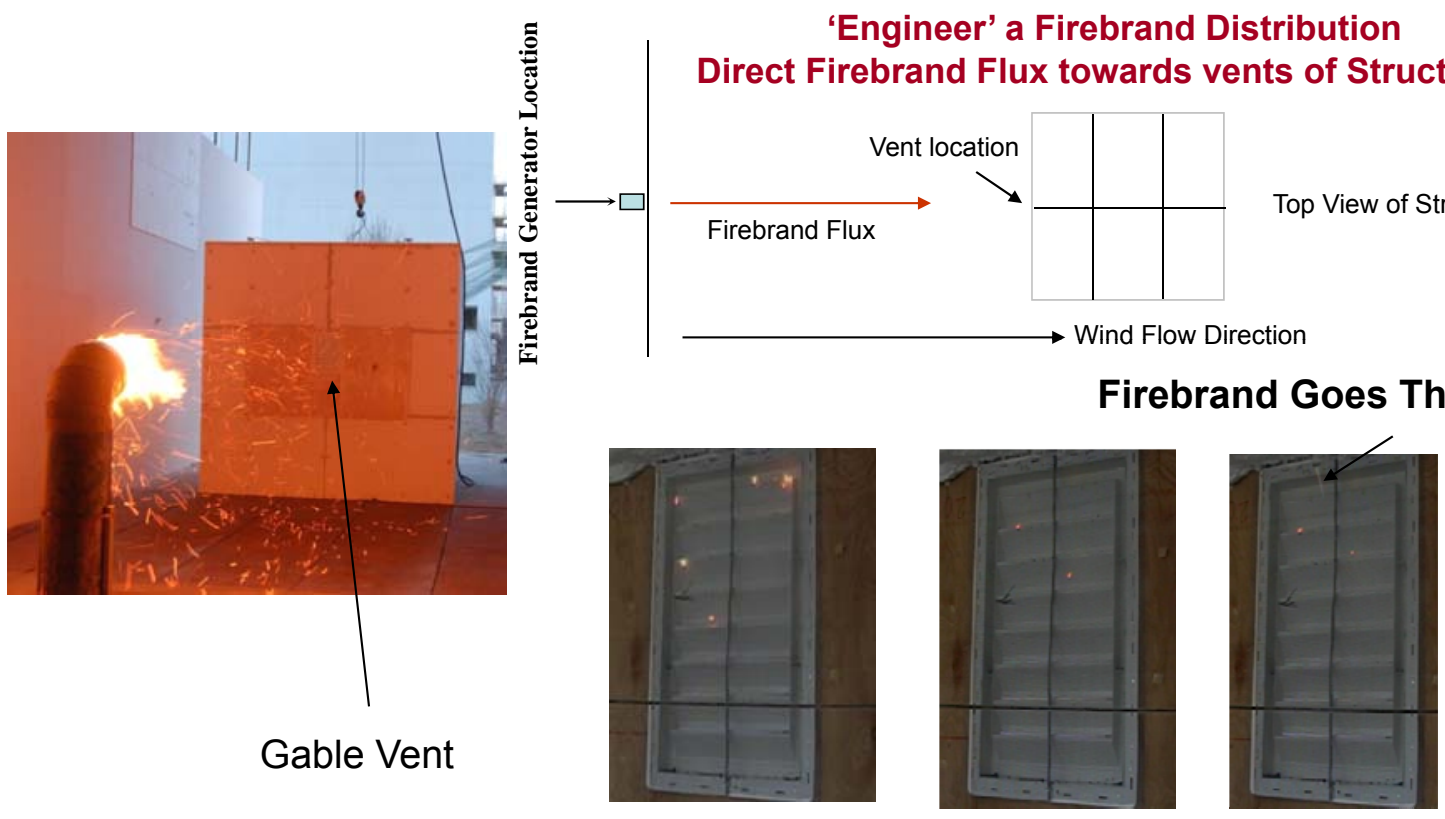




\section{Research Plan}

- Quantify firebrand penetration through building vents

- Full scale experiments at BRI

- Only full scale wind driven testing in the world

- Compare to new NIST reduced scale tests (Dragon's LAIR)

- Wind driven firebrand attack at reduced scale

- 6 mesh sizes (5.72 $\mathrm{mm}$ to $1.04 \mathrm{~mm}$ )

- Four types of ignitable materials behind mesh

- Cotton,

- Shredded Paper,

- OSB - Wood Crevice (filled with shredded paper)

- OSB - Wood Crevice (bare - no shredded paper)

\section{BRI/NIST Full Scale Experiments}

$20 \times 20$ mesh $(1.04 \mathrm{~mm})$ is shown

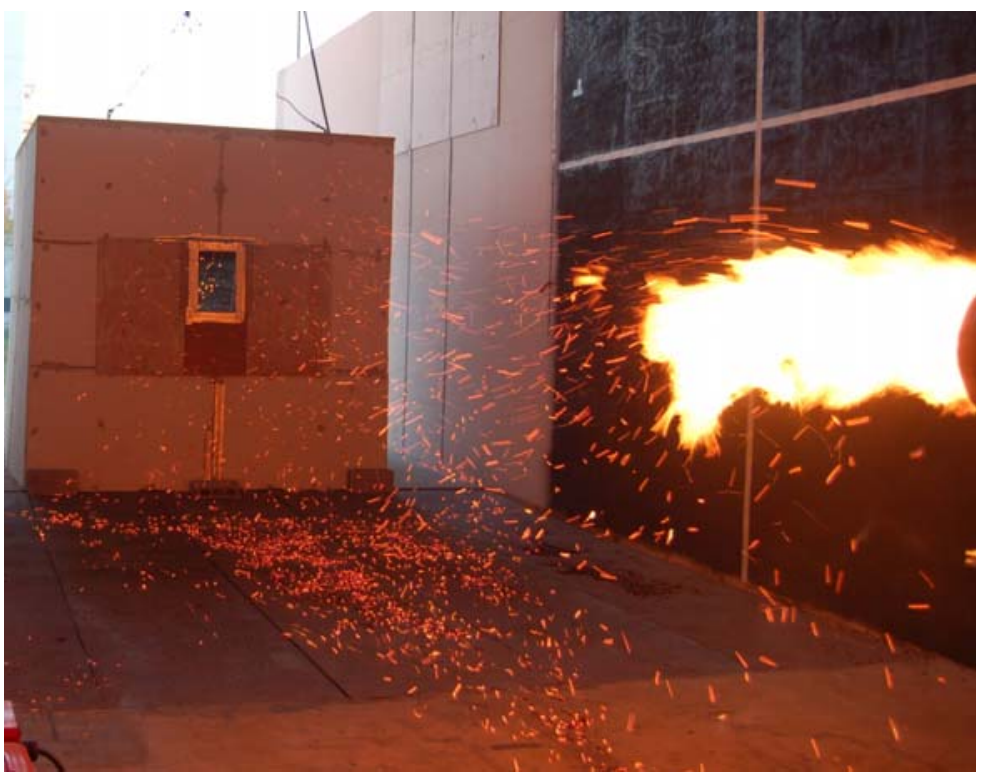




\section{Summary of BRI/NIST Results}

- SI - Smoldering Ignition; FI - Flaming Ignition

- NI-No Ignition

- Each case - three repeat experiments

\begin{tabular}{|c|c|c|c|c|}
\hline Mesh & Paper & Cotton & Crevice & $\begin{array}{c}\text { Crevice with } \\
\text { paper }\end{array}$ \\
\hline $\begin{array}{c}4 \times 4 \\
(5.72 \mathrm{~mm})\end{array}$ & SI to FI & SI & SI & $\begin{array}{l}\text { SI to FI (paper) } \\
\text { SI (OSB) }\end{array}$ \\
\hline $\begin{array}{c}8 \times 8 \\
(2.74 \mathrm{~mm})\end{array}$ & SI to FI & SI & SI & $\begin{array}{l}\text { SI to FI (paper) } \\
\text { SI (OSB) }\end{array}$ \\
\hline $\begin{array}{l}10 \times 10 \\
(2.0 \mathrm{~mm})\end{array}$ & SI to FI & SI & NI & $\begin{array}{l}\text { SI to FI (paper) } \\
\text { (SI OSB) }\end{array}$ \\
\hline $\begin{array}{c}14 \times 14 \\
(1.55 \mathrm{~mm})\end{array}$ & SI & SI & NI & $\begin{array}{l}\text { SI (paper) } \\
\text { SI (OSB) }\end{array}$ \\
\hline $\begin{array}{c}16 \times 16 \\
(1.35 \mathrm{~mm})\end{array}$ & SI & SI & NI & NI \\
\hline $\begin{array}{c}20 \times 20 \\
(1.04 \mathrm{~mm})\end{array}$ & $\begin{array}{c}\text { Two tests: NI; } \\
\text { One test SI }\end{array}$ & $\begin{array}{l}\text { Two tests: SI } \\
\text { One Test NI }\end{array}$ & NI & NI \\
\hline
\end{tabular}

NLT

National Institute of Standards and Technology

\section{Mesh Effectiveness}

BRI/NIST full scale and NIST reduced scale tests - mesh is not effective

(a) Front view

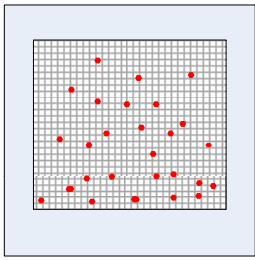

\section{Mesh not effective!}

(b) Side view
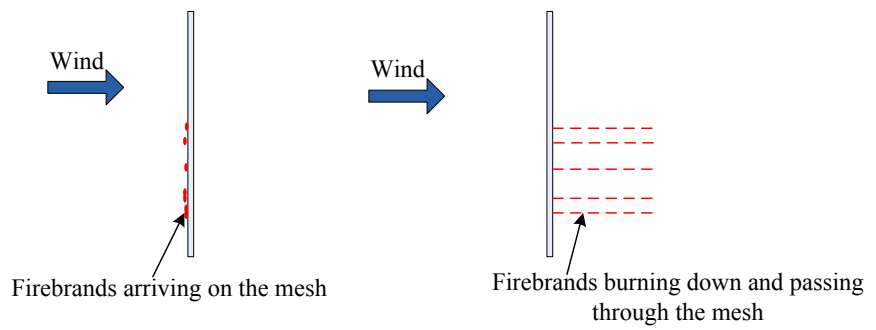


\section{Exposing Siding Treatments, Walls Fitted with Eaves, and Glazing Assemblies to Firebrand Showers}

NLT

National Institute of Standards and Technology

\section{Research Plan}

- Determine siding treatment vulnerability to firebrand showers

- Do firebrands become trapped within corner post/under siding itself?

- Determine glazing assembly vulnerability to firebrand showers

- Do firebrands accumulate inside corner of framing of glazing assemblies, and lead to window breakage?

- Determine eave vulnerability to firebrand showers

- Do firebrands become lodged within joints between walls/eave overhang?

- Determine if fine fuels adjacent to structure can produce ignition

\section{First experiments ever conducted}




\section{Workshop Held For Testing Input in CA}

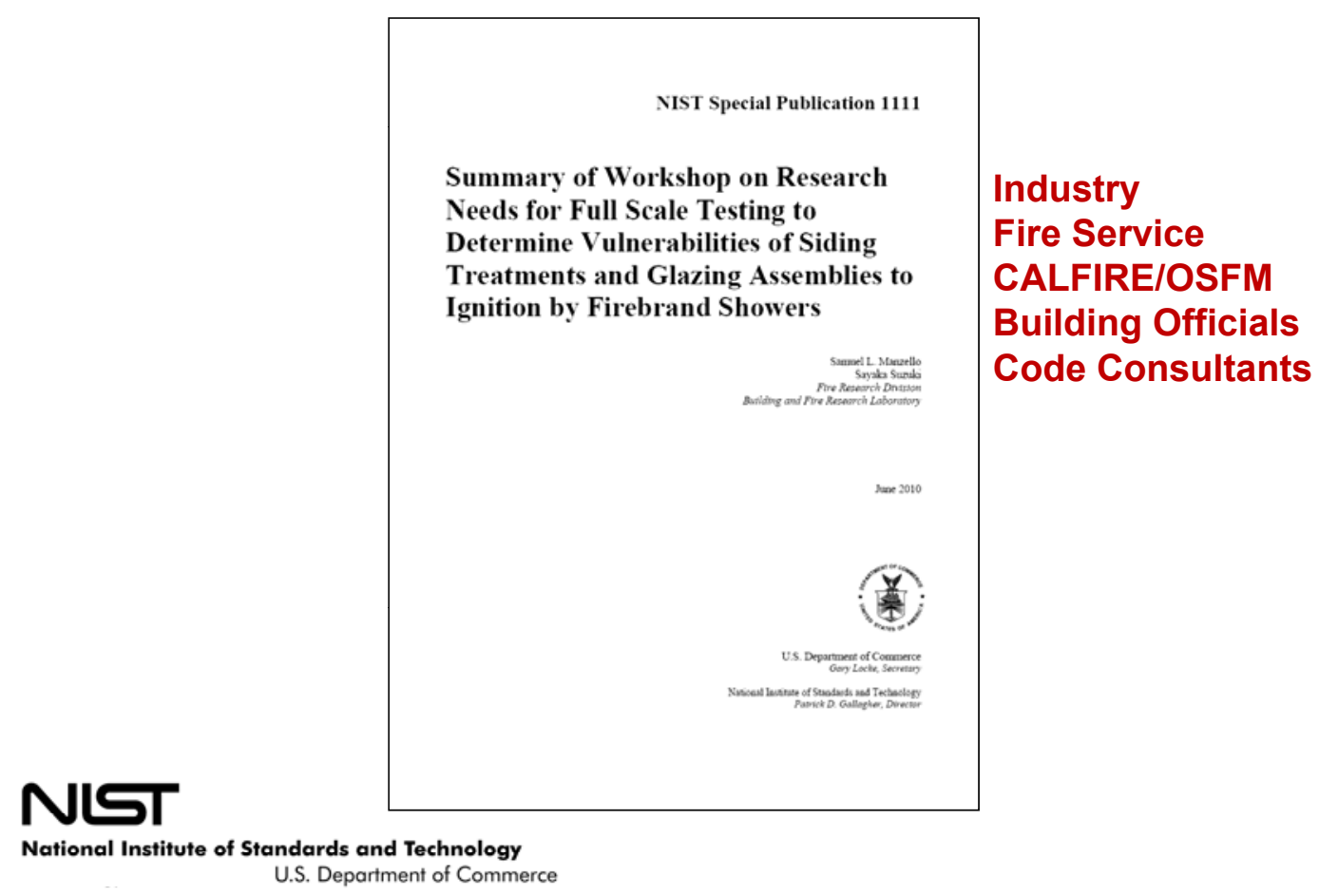

\section{Siding Treatments}

- Corner - believed that firebrands may become trapped within the corner post and under the siding itself

- OSB, moisture barrier applied (OSB dried; $11 \%$ )
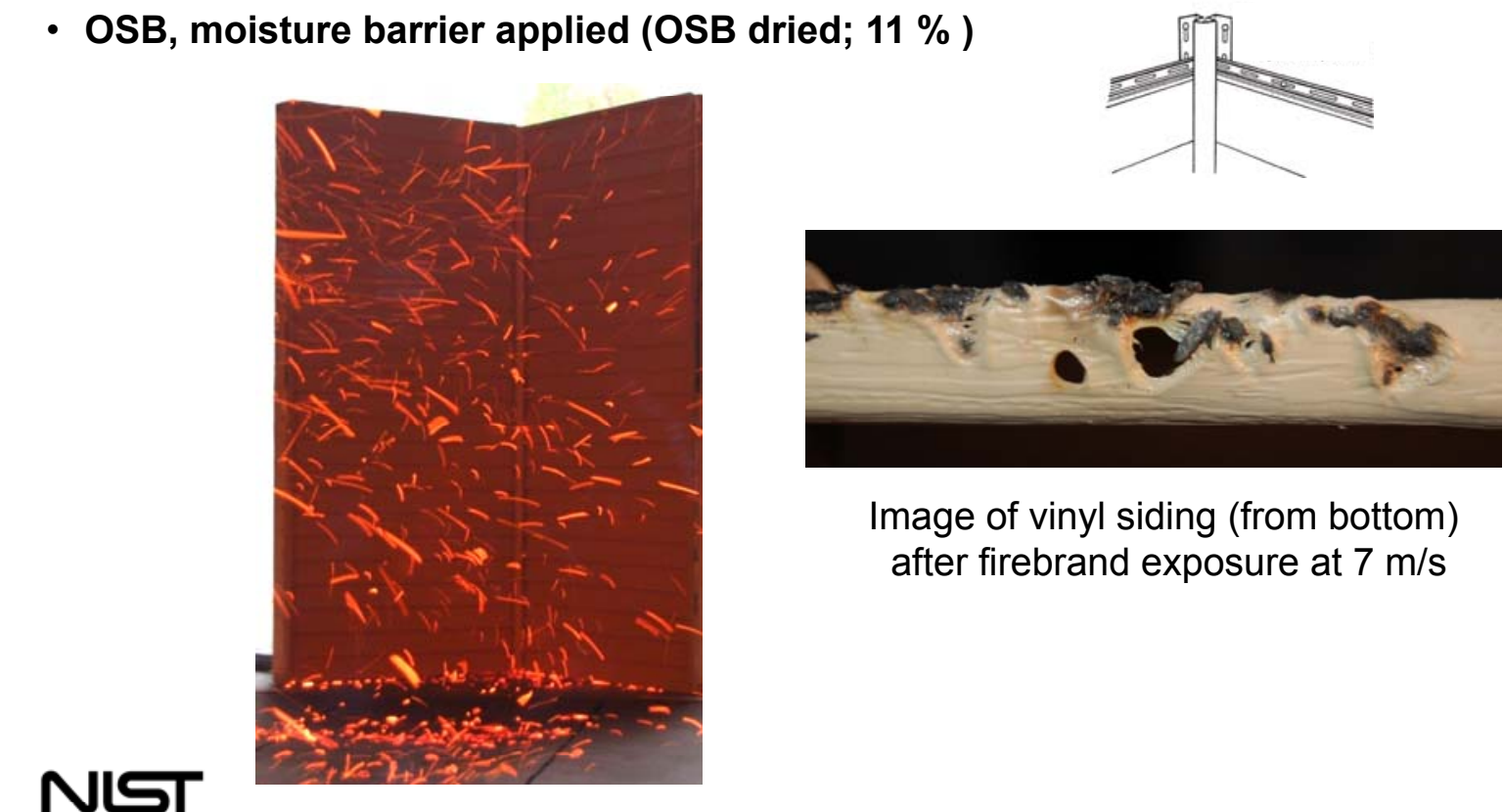

Image of vinyl siding (from bottom) after firebrand exposure at $7 \mathrm{~m} / \mathrm{s}$ 


\section{Siding Treatment Results}

Polypropylene siding is newer to the market; used as has the look/feel of cedar siding

\begin{tabular}{|c|c|c|c|c|}
\hline $\mathbf{U}_{\infty}(\mathbf{m} / \mathbf{s})$ & $\begin{array}{c}\text { Vinyl Siding } \\
\text { OSB Sheathing } \\
\text { Dried }\end{array}$ & $\begin{array}{c}\text { Vinyl Siding } \\
\text { OSB Sheathing } \\
\text { Not Dried }\end{array}$ & $\begin{array}{c}\text { Polyproplylene } \\
\text { Siding } \\
\text { OSB Sheathing } \\
\text { Dried }\end{array}$ & $\begin{array}{c}\text { Polyproplylene } \\
\text { Siding } \\
\text { OSB Sheathing } \\
\text { Not Dried }\end{array}$ \\
\hline $\mathbf{7}$ & $\begin{array}{c}\text { Siding } \\
\text { melted/holes } \\
\text { Burns on Tyvek } \\
\text { OSB NI }\end{array}$ & $\begin{array}{c}\text { Siding } \\
\text { melted/holes } \\
\text { Burns on Tyvek } \\
\text { OSB NI }\end{array}$ & $\begin{array}{c}\text { Siding melted } \\
\text { Burns on Tyvek } \\
\text { OSB NI }\end{array}$ & $\begin{array}{c}\text { Siding melted } \\
\text { Burns on Tyvek } \\
\text { OSB NI }\end{array}$ \\
\hline $\mathbf{9}$ & $\begin{array}{c}\text { Siding } \\
\text { melted/holes } \\
\text { Burns on Tyvek } \\
\text { OSB SI }\end{array}$ & $\begin{array}{c}\text { Siding } \\
\text { melted/holes } \\
\text { Burns on Tyvek } \\
\text { OSB NI }\end{array}$ & $\begin{array}{c}\text { Siding melted } \\
\text { Burns on Tyvek } \\
\text { OSB NI }\end{array}$ & $\begin{array}{c}\text { Siding melted } \\
\text { Burns on Tyvek } \\
\text { OSB NI }\end{array}$ \\
\hline
\end{tabular}

NLT

National Institute of Standards and Technology

\section{Eave Vulnerability}

- A very important, long standing question is whether firebrands may become lodged within joints between walls and the eave overhang

- There are essentially two types of eave construction commonly used in California and the USA

- Open eave

- Boxed in eave

- In open eave construction, the roof rafter tails extend beyond the exterior wall and are readily visible

- In the second type of eave construction, known as boxed in eave construction, the eaves are essentially enclosed and the rafter tails are no longer exposed

Firebrand accumulation in eaves Does this really happen??

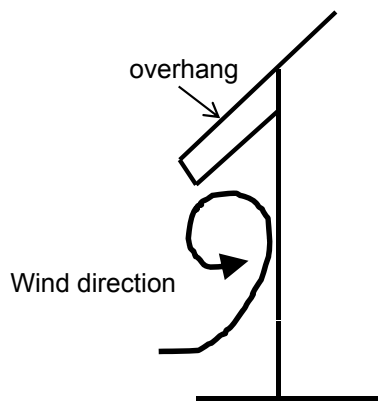




\section{Typical Open Eave Construction}

- Since the open eave construction is thought to the worst possible situation, this configuration was used

- Common construction type used in CA shown
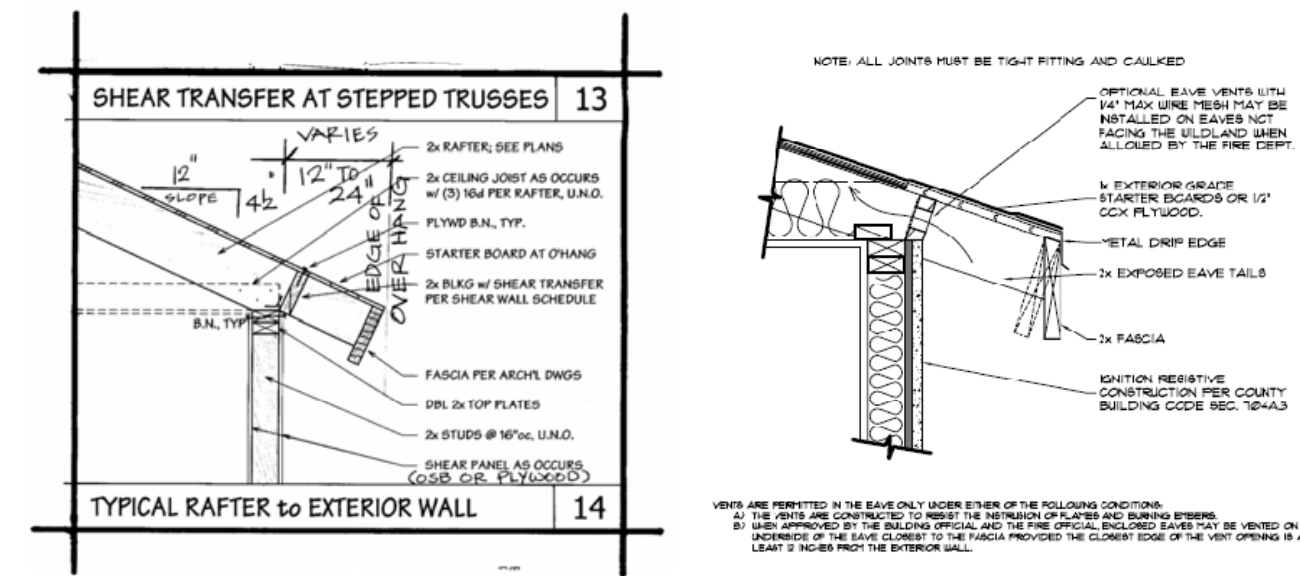

NLT

National Institute of Standards and Technology

U.S. Department of Commerce

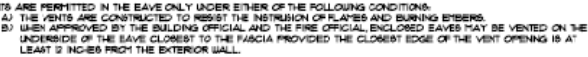

\section{Walls Fitted With Eaves}

Images of eave assemblies constructed for testing

Open eave construction is thought to the worst possible situation, this configuration was used

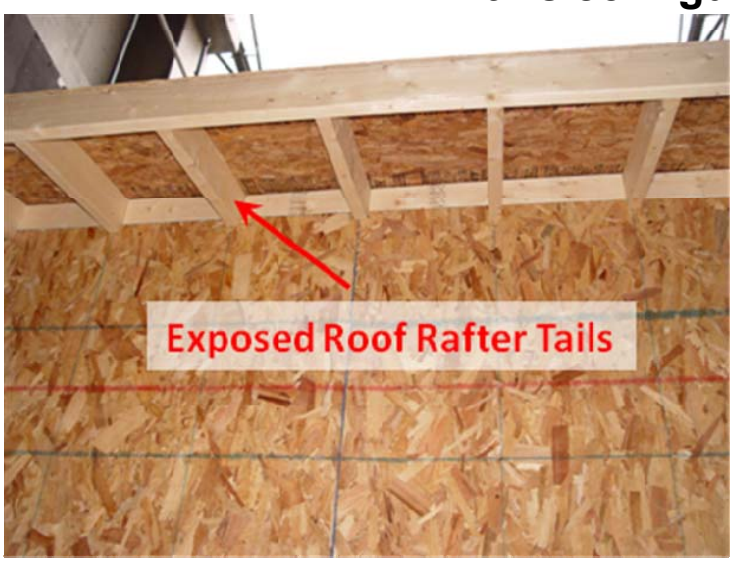

Wall Size: $2.44 \mathrm{~m}$ by $2.44 \mathrm{~m}$ Eave Overhang: $61 \mathrm{~cm}(2 \mathrm{ft})$

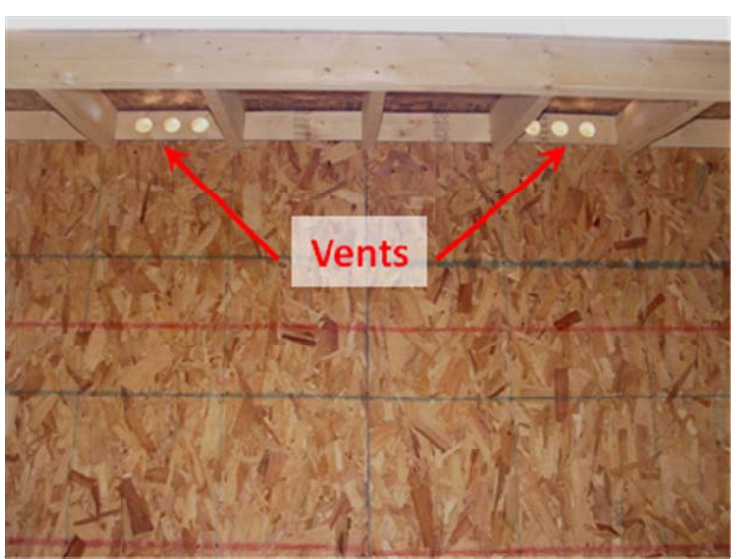

Vent holes: $50 \mathrm{~mm}(2 ")$

fitted with mesh $2.75 \mathrm{~mm}$ opening 


\section{Wall Fitted With Eave Exposed to Firebrand Showers}

\section{NLT}

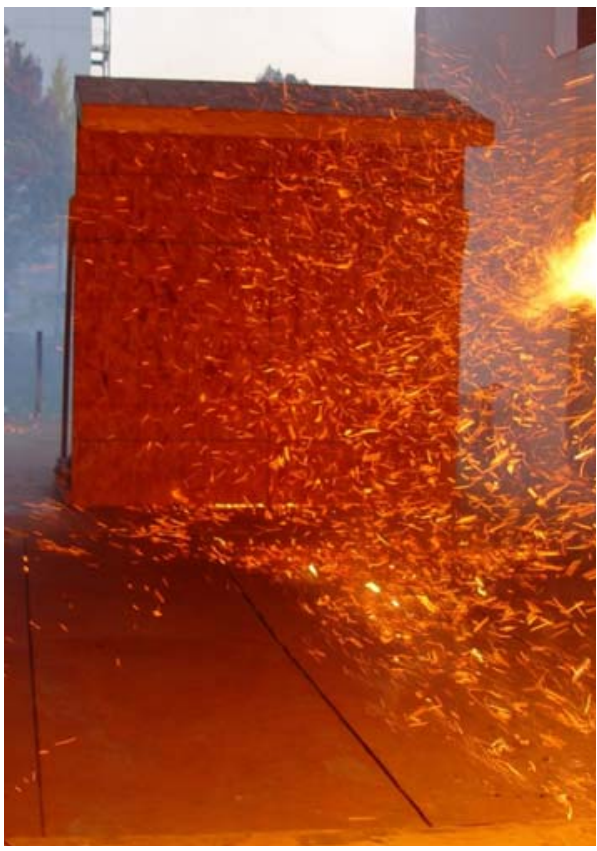

\section{CFD Simulations}

Only air profiles shown

Under eave, little or no flow velocity required to drive firebrands into joints between eave and wall assembly

\section{EXPERIMENTS NEEDED UNDER HIGHER WIND SPEEDS}
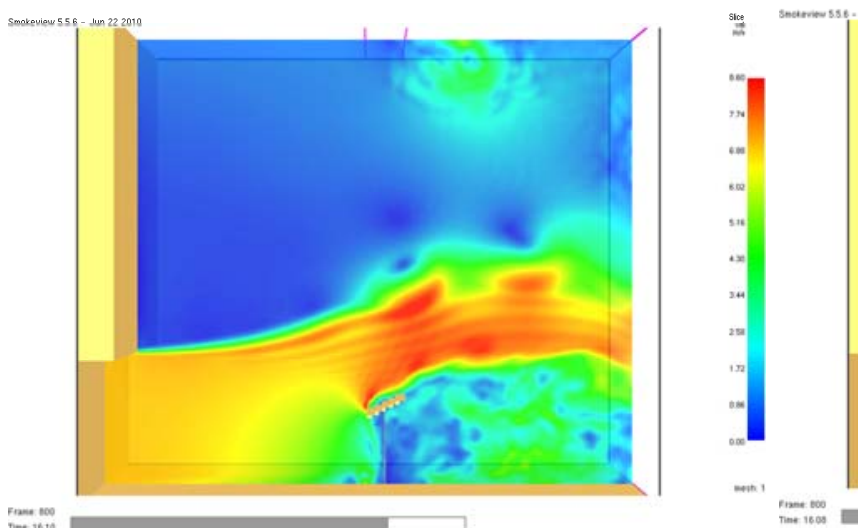


\section{Wall Fitted With Eave Results}

- The number of firebrands arriving at the vent locations increased as the wind speed increased

- Yet was very small as compared to the number of firebrands that bombarded the wall/eave assembly

\begin{tabular}{|c|c|c|}
\hline $\mathbf{U}_{\infty}(\mathbf{m} / \mathbf{s})$ & Open Eave With No Vents & Open Eave with Vents \\
\hline 7 & No Accumulation & 11 Firebrands Arrived at Vents \\
\hline 9 & No Accumulation & 28 Firebrands Arrived at Vents \\
\hline
\end{tabular}

NLT

National Institute of Standards and Technology

\section{Wall Fitted With Eave Results}

- The base of the wall actually ignited due to the accumulation of firebrands $(9 \mathrm{~m} / \mathrm{s})$

- It was very easy to produce ignition outside the structure since many firebrands were observed to accumulate in front of the structure during the tests

- Although some firebrands were observed to enter the vents, the ignition of the wall assembly itself demonstrates the dangers of wind driven firebrand showers

- The base of wall assembly ignited without the presence of other combustibles that may be found near real structures (e.g. mulch, vegetation) 


\section{Glazing Assemblies}

Do firebrands become trapped, accumulate inside the corner of the framing of glazing assemblies, and lead to window breakage?

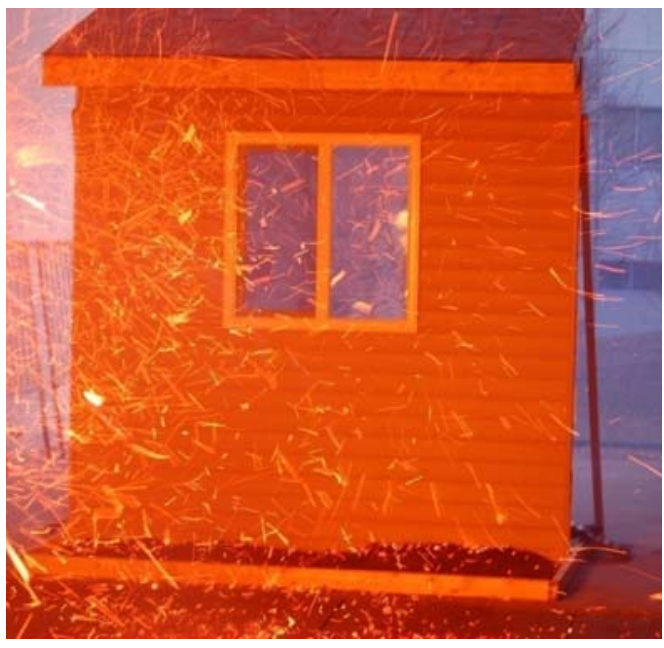

Vertically and Horizontally Sliding Window Assemblies

\section{Firebrand Accumulation in Front of Obstacles}




\section{Firebrand Accumulation}
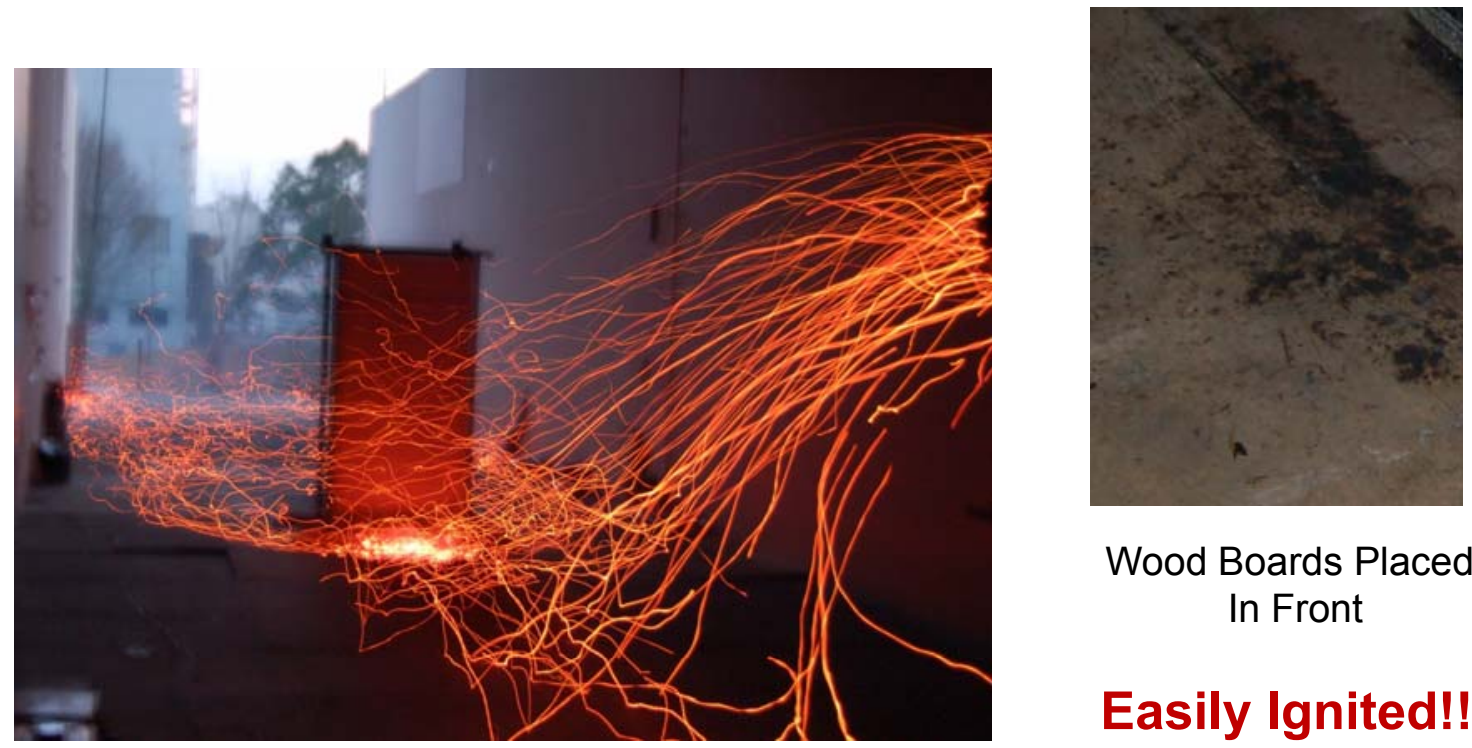

Wood Boards Placed In Front

Easily Ignited!!!

\section{NLT}

National Institute of Standards and Technology

U.S. Department of Commerce

\section{Fine Fuels Near Structure}

\section{Wall Ignited}

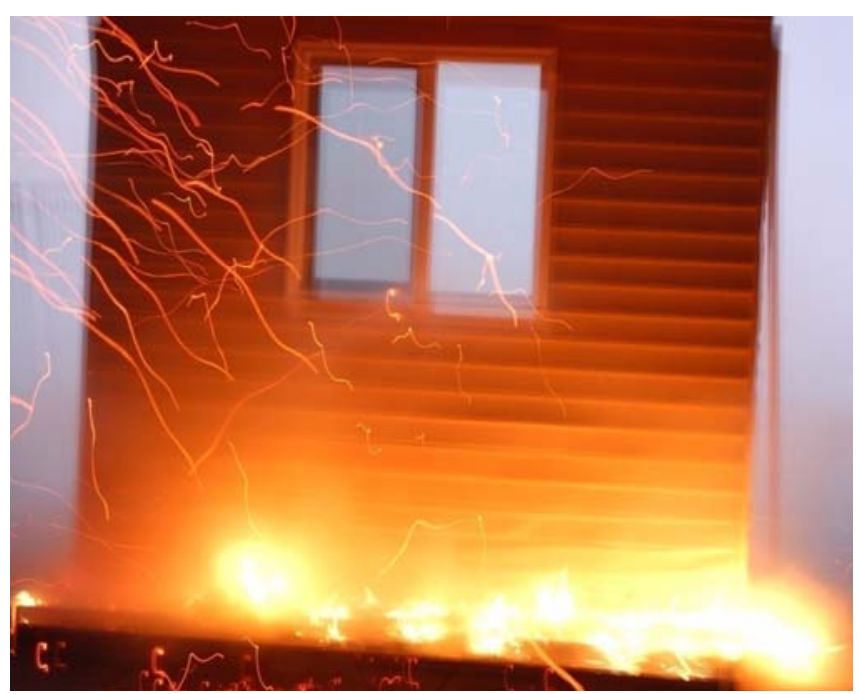

\section{NLT}




\section{Obstacles in Flow}

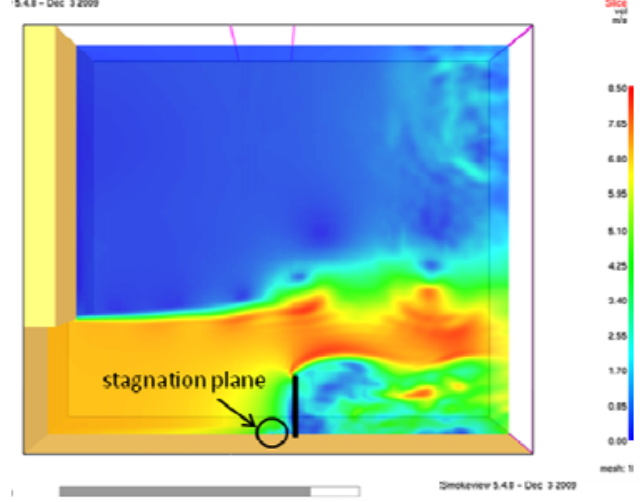

$1 \mathrm{~m}$ by $2 \mathrm{~m}$

NLT
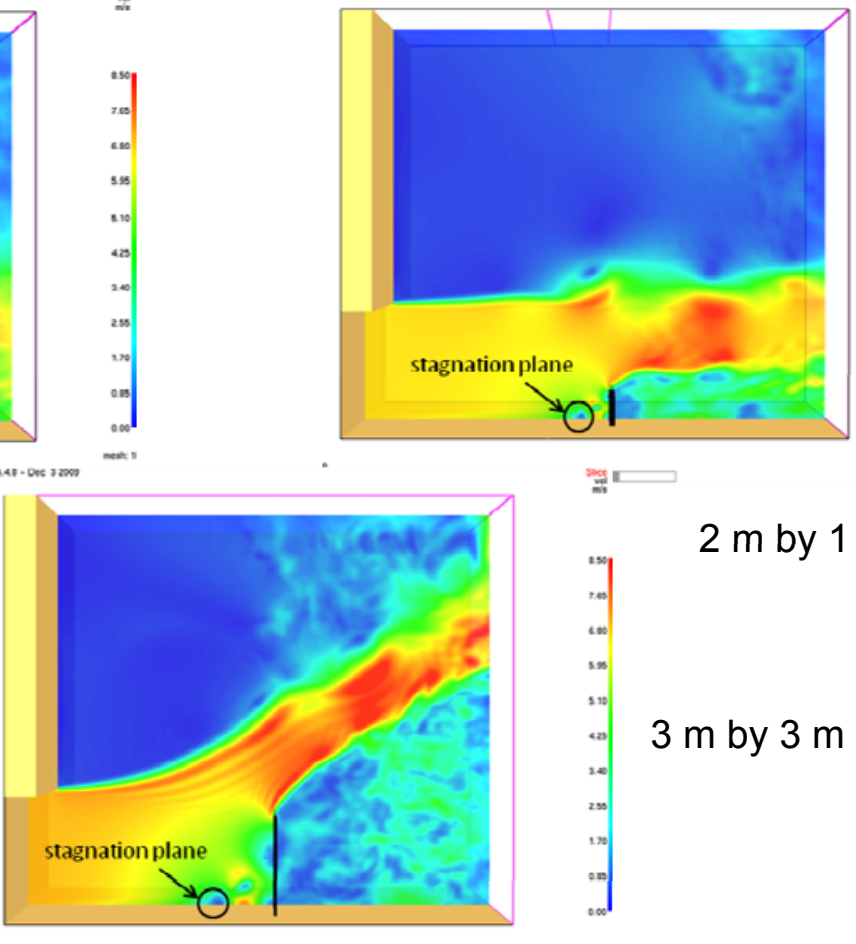

쫋나

$2 \mathrm{~m}$ by $1 \mathrm{~m}$

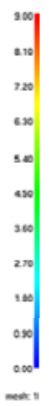

|

National Institute of Standards and

U.S. Department of Commerce

\section{Firebrand Production from Building Components}




\section{Work in Progress}

- Firebrand generation from:

- Structure Components

\section{NLT}

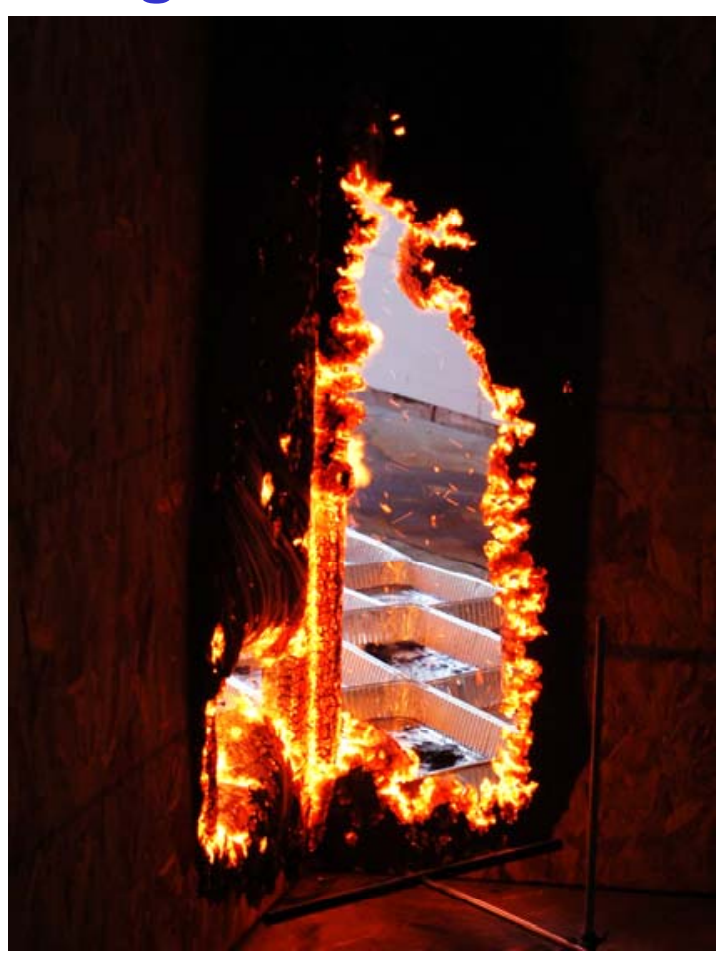

National Institute of Standards and Technology

U.S. Department of Commerce

\section{NIST Reduced Scale Building NIST Dragon's LAIR}




\section{NIST Dragon's LAIR (Lofting and Ignition Research)}

Couple 'Baby Dragon' with wind tunnel

Reproduced results from full scale tests

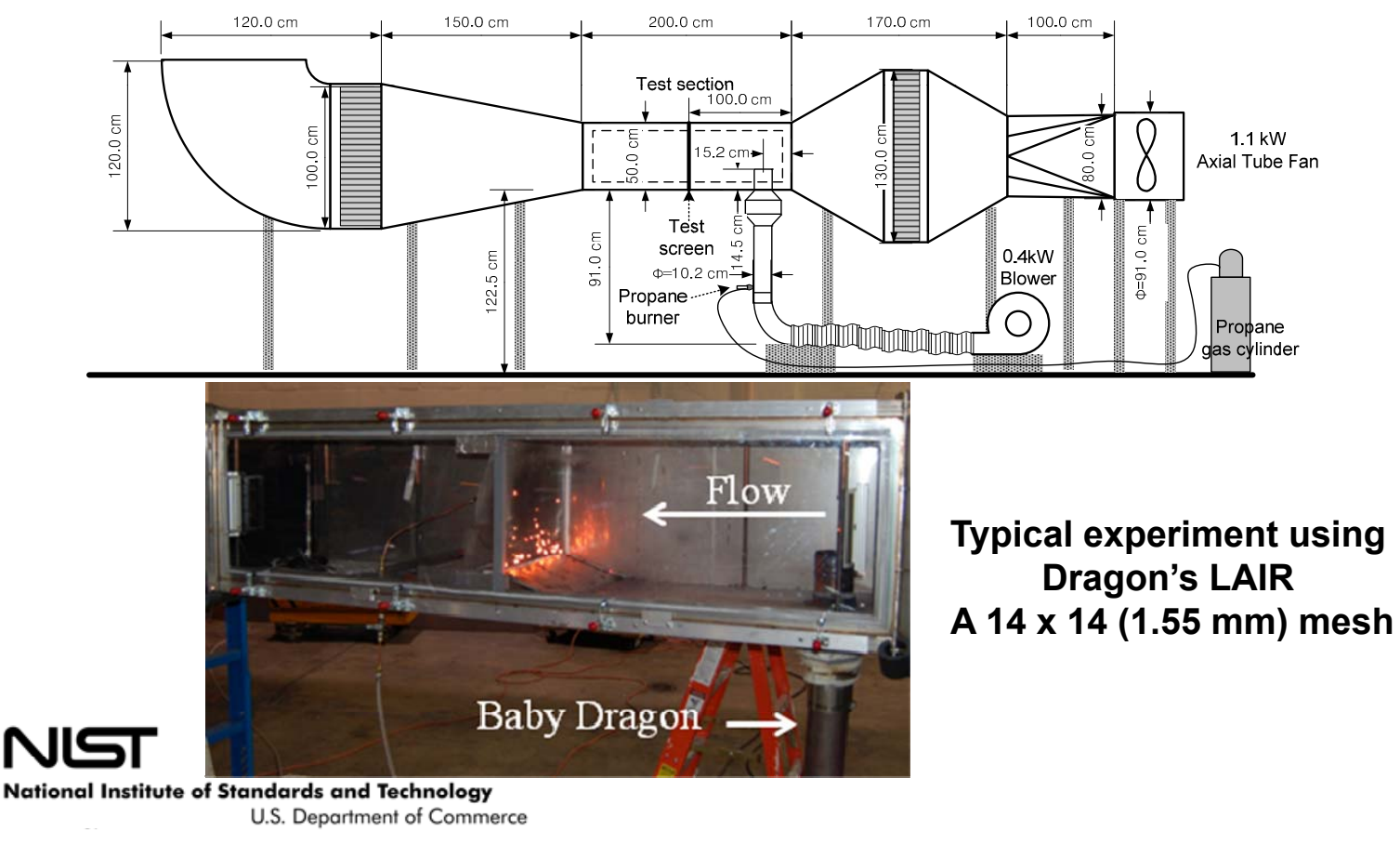

\section{Summary of NIST Results}

- SI - Smoldering Ignition; FI - Flaming Ignition; NI - No Ignition

- Velocities behind mesh matched to full scale experiments

- Mesh assembly - same area as full scale experiments $-1600 \mathrm{~cm}^{2}$

\begin{tabular}{|c|c|c|c|c|}
\hline Mesh & Paper & Cotton & Crevice & $\begin{array}{c}\text { Crevice with } \\
\text { paper }\end{array}$ \\
\hline $\begin{array}{c}4 \times 4 \\
(5.72 \mathrm{~mm})\end{array}$ & SI to FI & SI to FI & SI & $\begin{array}{l}\text { SI to FI (paper) } \\
\text { SI (OSB) }\end{array}$ \\
\hline $\begin{array}{c}8 \times 8 \\
(2.74 \mathrm{~mm})\end{array}$ & SI to FI & SI & SI & $\begin{array}{l}\text { SI to FI (paper) } \\
\text { SI (OSB) }\end{array}$ \\
\hline $\begin{array}{c}10 \times 10 \\
(2.0 \mathrm{~mm})\end{array}$ & SI to FI & SI & NI & $\begin{array}{l}\text { SI to FI (paper) } \\
\text { (SI OSB) }\end{array}$ \\
\hline $\begin{array}{c}14 \times 14 \\
(1.55 \mathrm{~mm})\end{array}$ & SI & SI & NI & $\begin{array}{l}\text { SI (paper) } \\
\text { SI (OSB) }\end{array}$ \\
\hline $\begin{array}{c}16 \times 16 \\
(1.35 \mathrm{~mm})\end{array}$ & SI & SI & NI & NI \\
\hline $\begin{array}{c}20 \times 20 \\
(1.04 \mathrm{~mm})\end{array}$ & NI & SI & NI & NI \\
\hline
\end{tabular}




\section{Continuous Feed Baby Dragon}

- Generate continuous firebrand showers

- Coupled to Dragon's LAIR

Ability to rate materials To firebrand exposure

NLT

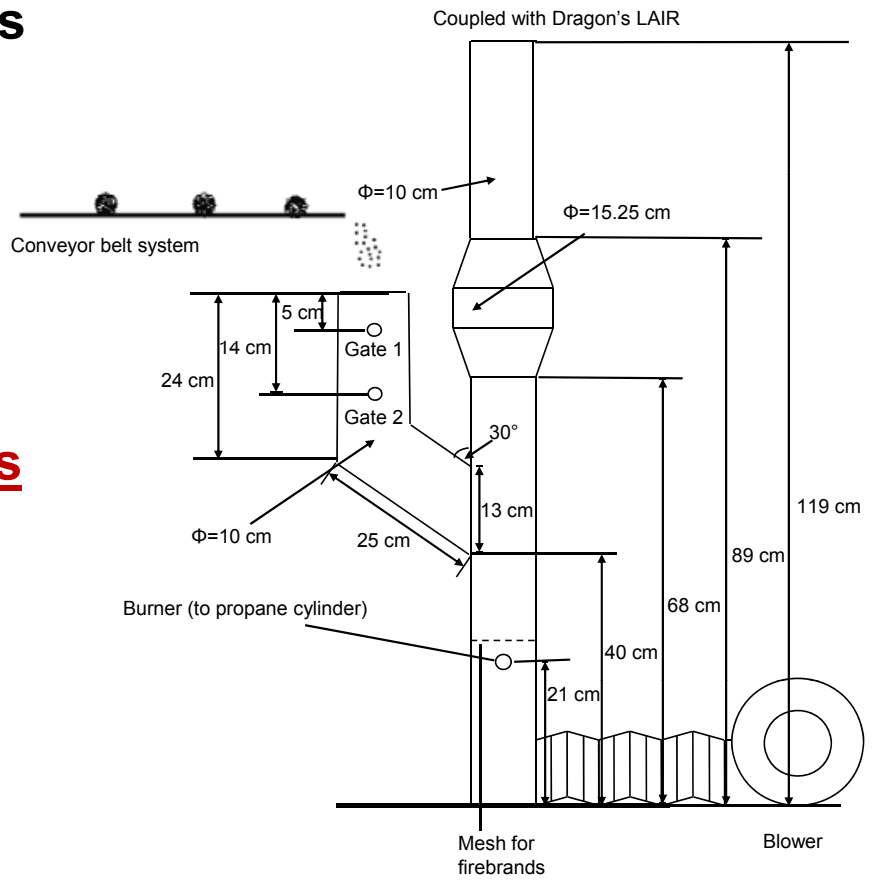

National Institute of Standards and Technology

\section{Improved NIST Dragon's LAIR (Lofting and Ignition Research)}

Expose materials to continuous, wind driven firebrand showers

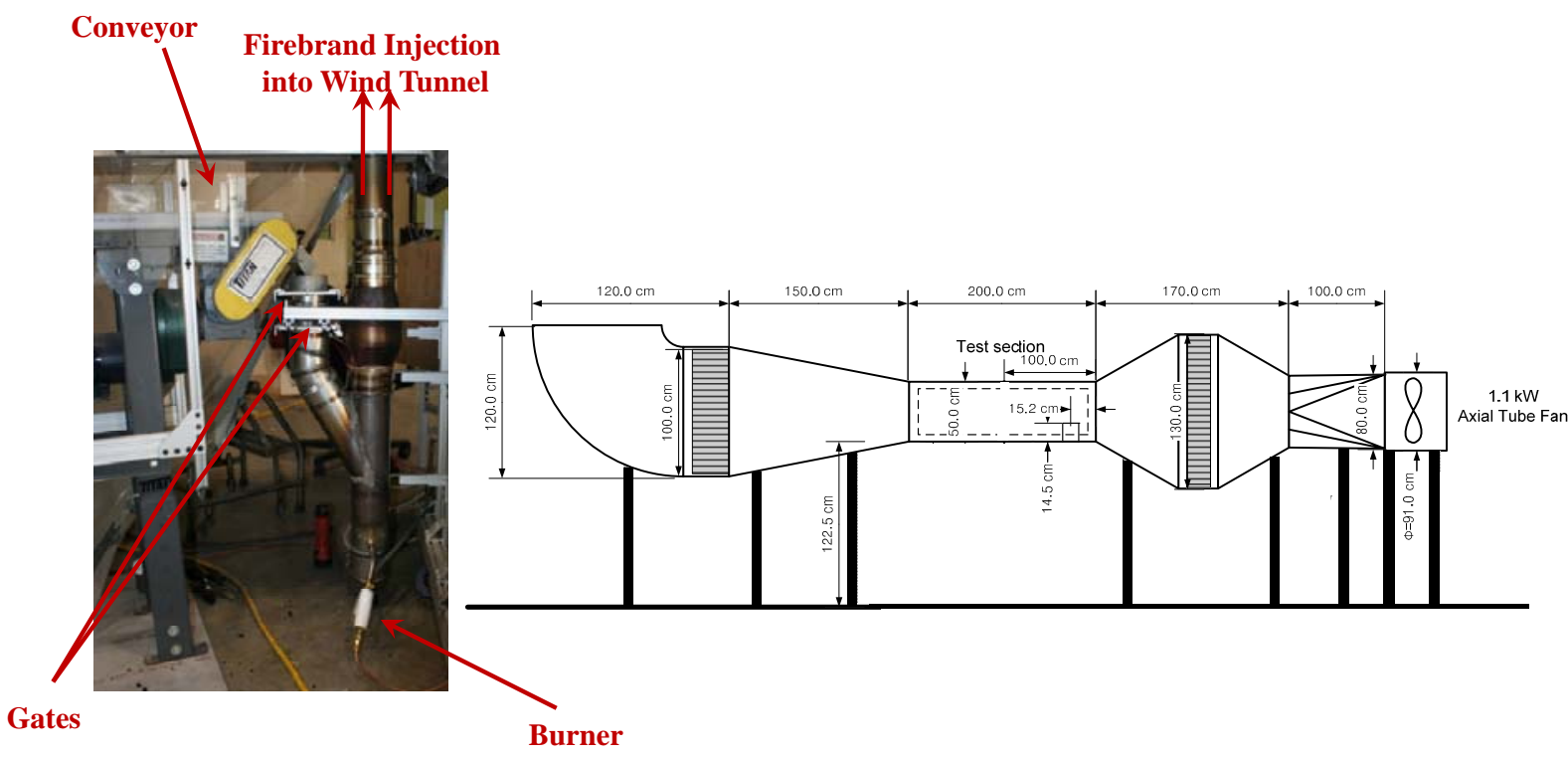




\section{Improved NIST Dragon's LAIR}

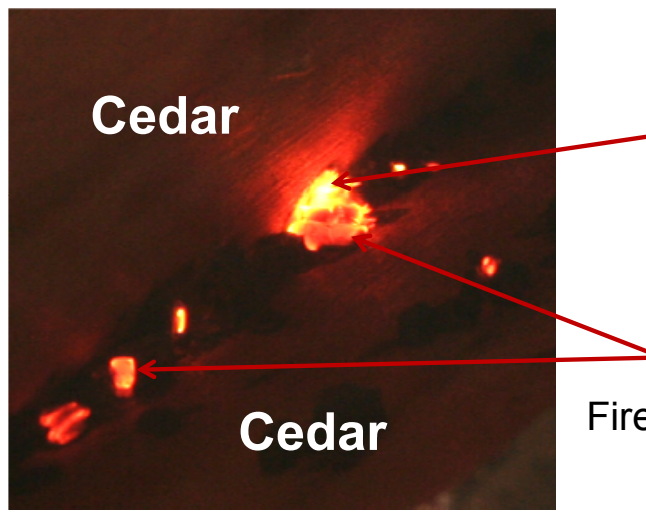

SI of Cedar

IGNITION REGIME MAPS

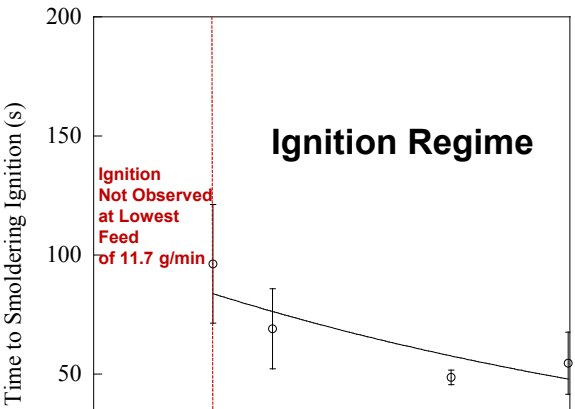

No Ignition Regime

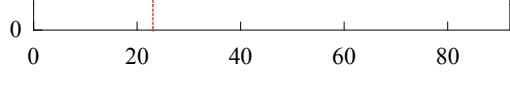

Feed Rate (g/min)

NGT

National Institute of Standards and Technology

U.S. Department of Commerce

\section{Developing Rapid Response Instrumentation Packages to Quantify Structure Ignition In Wildland-Urban Interface (WUI) Fires}




\section{WHAT IS THE NEW TECHNICAL IDEA?}

Field deployable instruments - heat flux, wind speed, firebrand generation

Quantify WUI Fire Exposures

NIST

National Institute of Standards and Technology

U.S. Department of Commerce

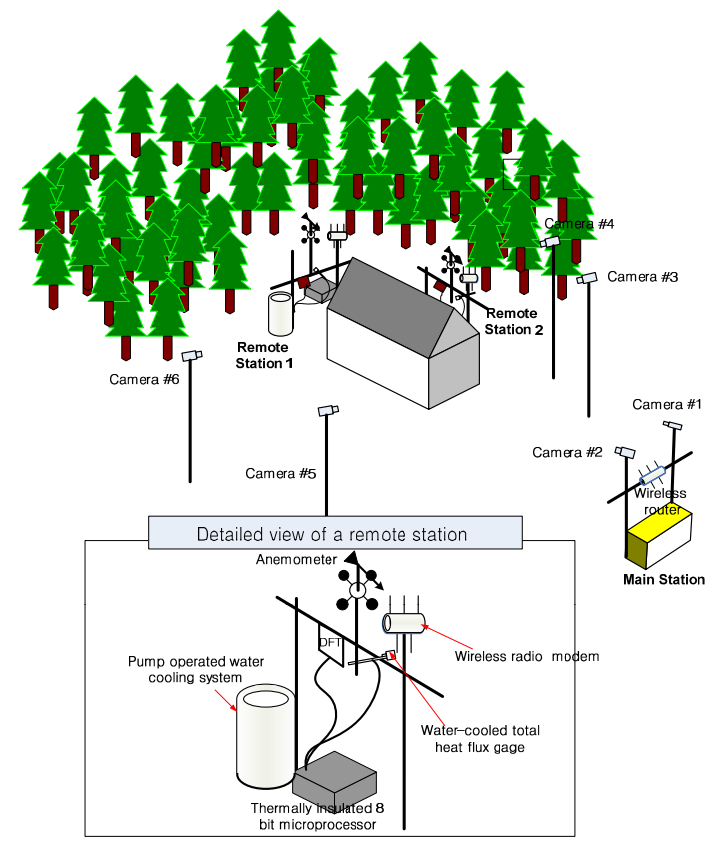

\section{Heat Flux as Fire Approached}

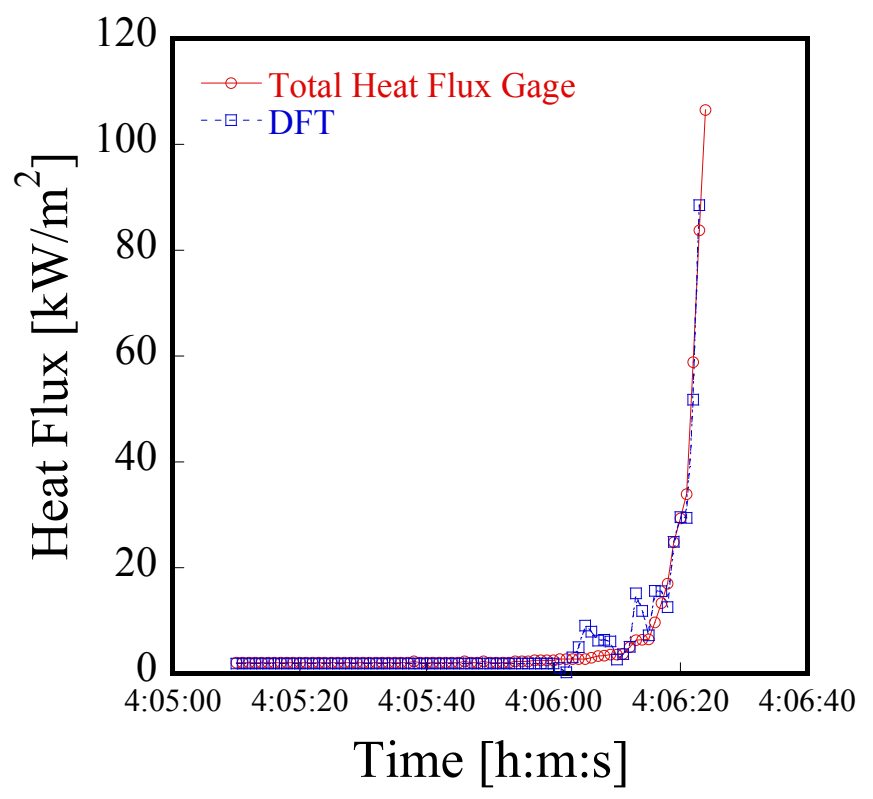




\section{Recent Impacts}

- State of New Jersey using NIST video in training courses

- Worked with CALFIRE as part of a task force (invitation only) to reduce mesh size used to cover building vent openings to lessen the potential hazard of firebrand entry into structures.

- Changes were formally adopted into the 2010 California Code of Regulations, Title 24, Part 2, Chapter 7A, and are effective January, 2011

- "Your research will certainly further our understanding of the risks of flying embers during a wildfire event, and will help guide us as we make recommendations to our policyholders on how to better protect their home from the threat of wildfires"

Stan Rivera - Chartis Insurance (http://www.chartisinsurance.com)

- Work has garnered the attention of Australian Government.

- $\quad A B C B$ is joint initiative of all levels of Australian Government

- $A B C B$ has requested a formal partnership with NIST to assess Australian Standards to see whether they can account for ignition vulnerabilities observed by firebrands

- IBHS has used NIST's Dragon concept for use in their wind tunnel facility to generate firebrand showers

NLT

National Institute of Standards and Technology

U.S. Department of Commerce

\section{Recent Publications}
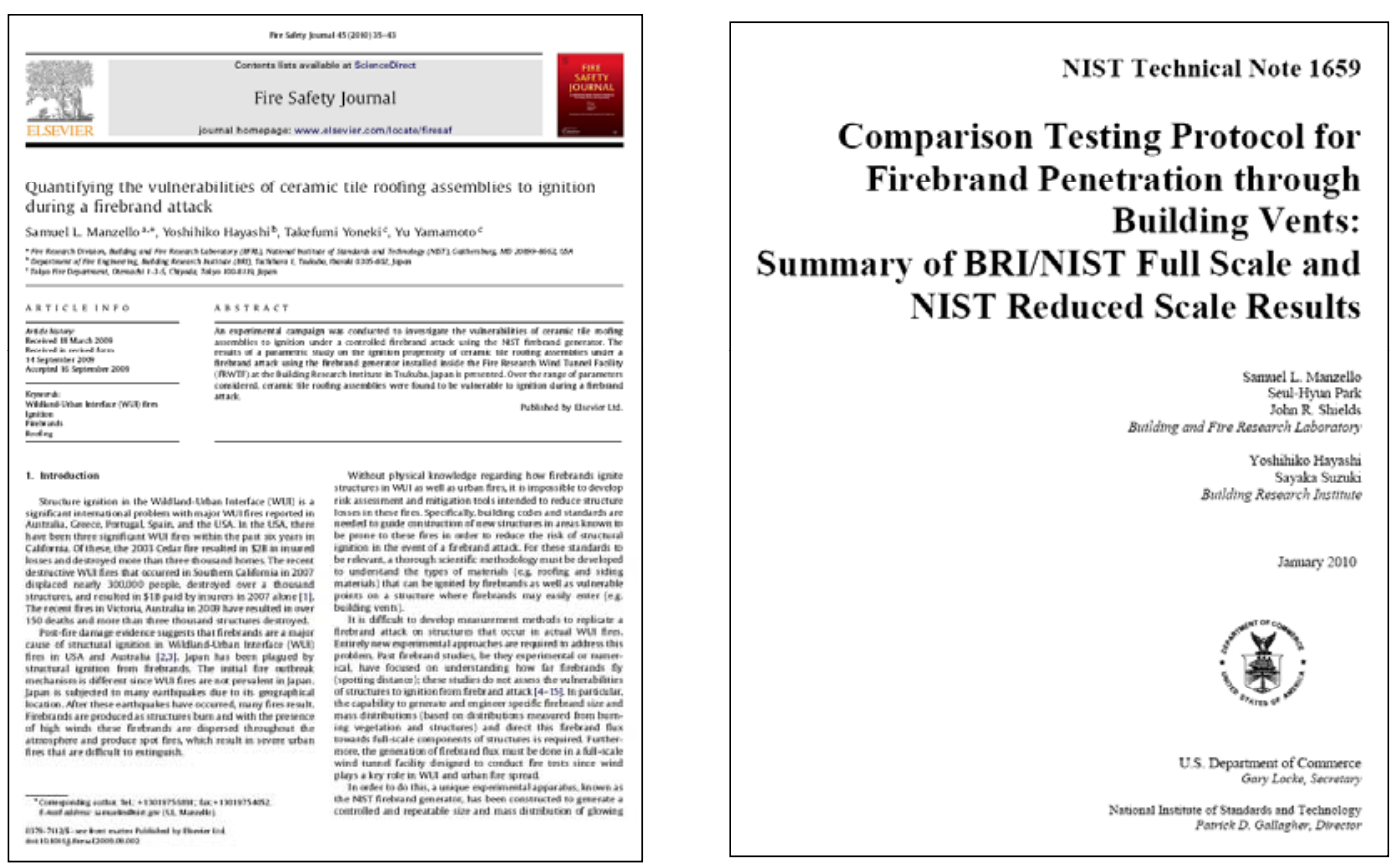

NIT

National Institute of Standards and Technology

U.S. Department of Commerce 


\section{Recent Publications}
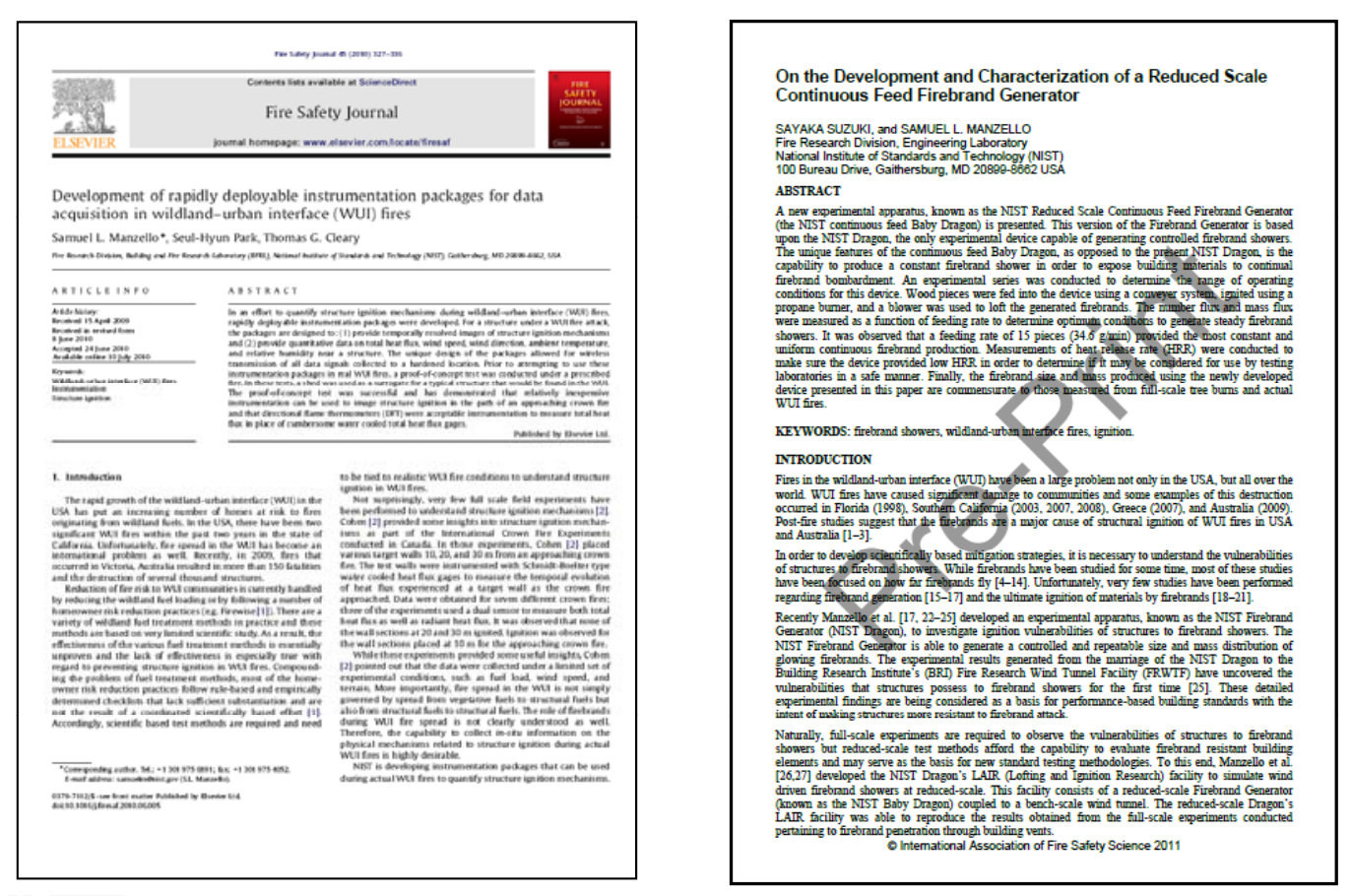

NLT

National Institute of Standards and Technology

U.S. Department of Commerce

\section{Summary}

- NIST Dragon coupled to BRI's FRWTF

- Capability to experimentally expose structures to wind driven firebrand showers for first time!

- Structure vulnerability experiments conducted for:

- Roofing (cermaic/asphalt)

- Vents/mesh (gable/different mesh sizes)

- Siding (vinyl, polypropylene, cedar)

- Eaves (open)

- NIST Dragon's LAIR Facility

- Capability to expose materials/firebrand resistant technologies to wind driven firebrand showers

- With newly developed Continuous Feed Baby Dragon, potential to evaluate and compare relative performance 


\section{Decking Vulnerabilities}

\section{NLT}

National Institute of Standards and Technology

U.S. Department of Commerce

Front view

eave

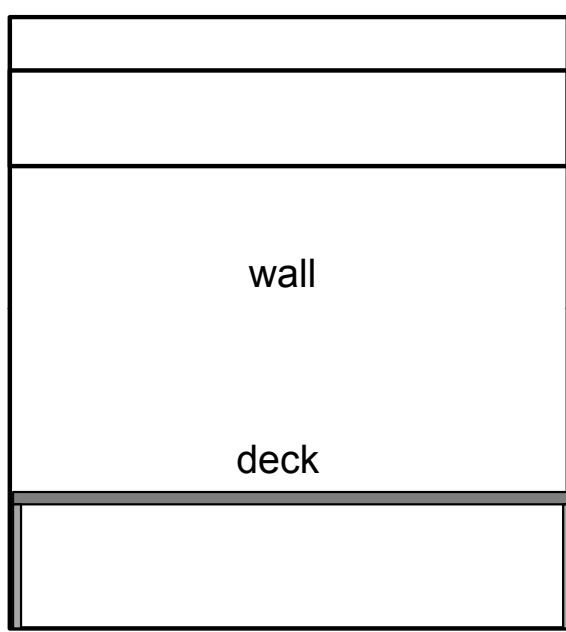

Supported by $2 \times 6$ Douglas-Fir

$8 \mathrm{ft}$

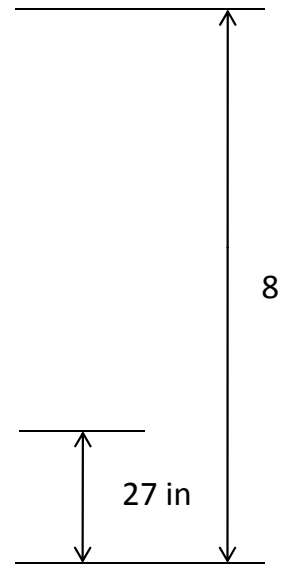

\section{Side view}

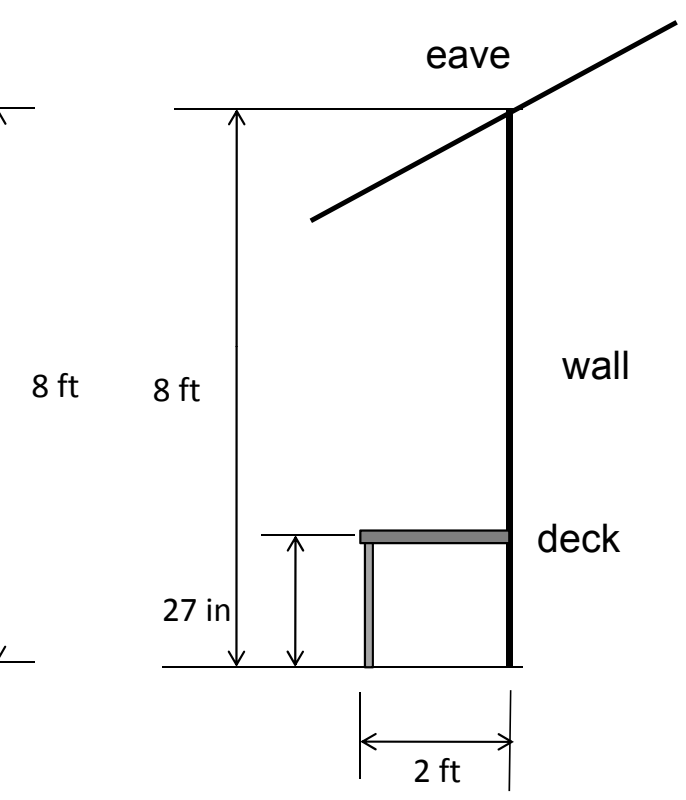

NLT

National Institute of Standards and Technology U.S. Department of Commerce 


\section{Board Materials}

- Wood (treated wood or wood which is naturally resistant to decaying)

- Treated pine

- Cedar

- Redwood

- Ipé

- Composite

- Wood/plastic

- Fiber/PVC

- Plastic

- Metal

NIST

National Institute of Standards and Technology

\section{Profiles}

Profiles---Depends on materials

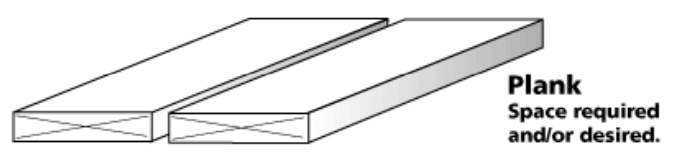

Plank ---wood or composite

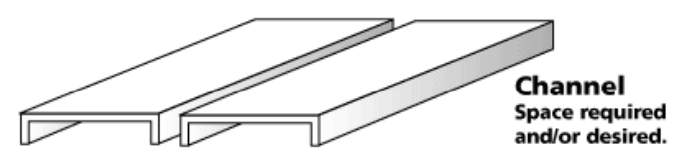

Channel---composite

Spacing between boards $5 \mathrm{~mm}$ between board ends $1 / 8^{\prime \prime}$ between board and wall $1 / 4^{\prime \prime}$

\section{NLT}




\section{Framing}

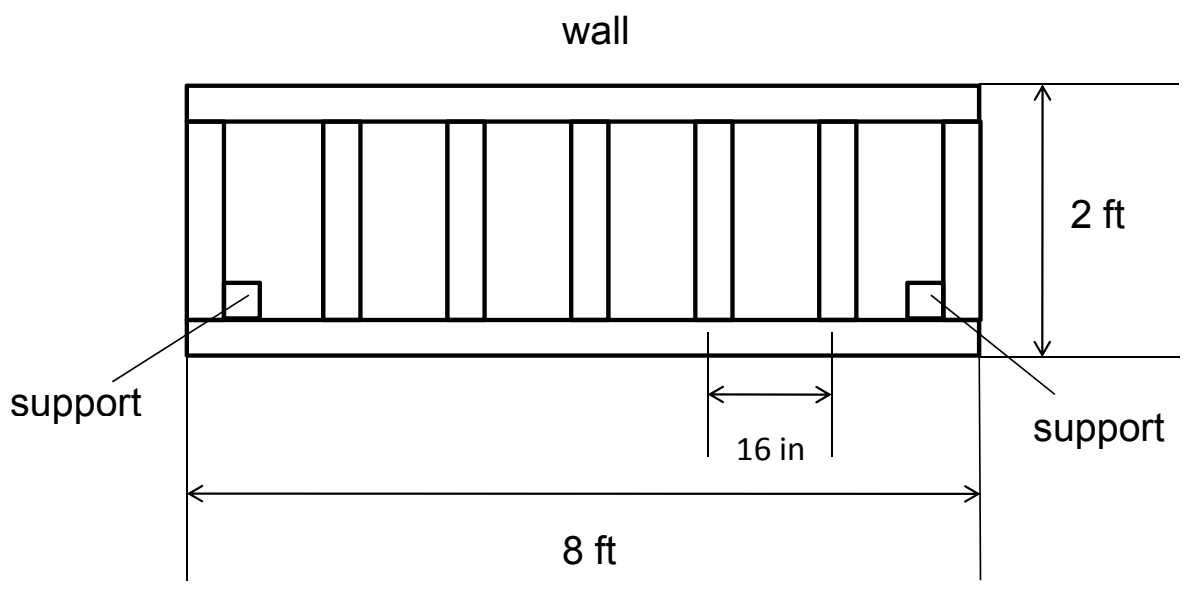

Made from $2 \times 8$

\section{NLT}

National Institute of Standards and Technology

U.S. Department of Commerce

\section{Patterns}

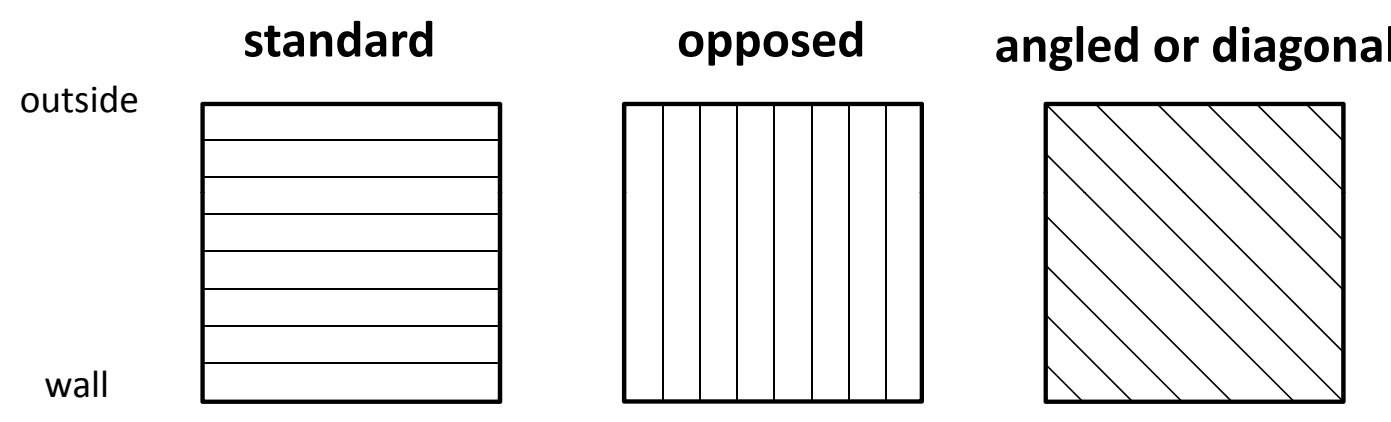

Which pattern is the easiest for firebrands to be stuck with? Or no difference? 


\section{Railing}

- Railing is needed??

- If yes,

- surface of deck is 30 inches above the ground

- railing is 36 inches above the surface of deck

- a sphere with a diameter of 4 inches cannot pass through the space between each rail or any gaps
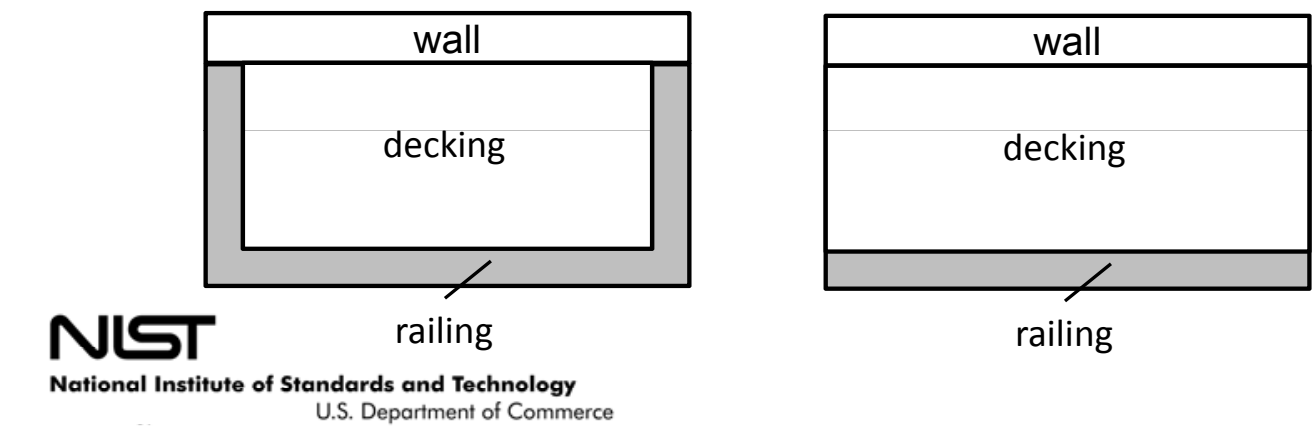

railing 
Appendix 3

\section{SFM STANDARD 12-7A-4}

12-7A-4.1 Application. The minimum design, construction and performance standards set forth herein for unloaded decks are those deemed necessary to establish conformance to the provisions of these regulations. Materials and assemblies that meet the performance criteria of this standard are acceptable for use as defined in California Building Standards Code.

12-7A-4.2 Scope. This standard evaluates the performance of decks (or other horizontal ancillary structures in close proximity to primary structures) when exposed to direct flames and brands. The under-deck flame exposure test is intended to determine the heat release rate (HRR) and degradation modes of deck or other horizontal boards when exposed to a burner flame simulating combustibles beneath a deck. The burning brand exposure test is intended to determine the degradation modes of deck or other horizontal boards when exposed to a burning brand on the upper surface.

\section{2-7A-4.3 Referenced document.}

1. ASTM D 4444, Test Methods for Use and Calibration of Hand-Held Moisture Meters.

2. ASTM E 108, Test Methods for Fire Tests of Roof Coverings.

3. California Building Code, Chapter 7A.

4. UL 790, Standard Test Methods for Fire Tests of Roof Coverings.

\section{2-7A-4.4 Definitions.}

1. Deck boards. Horizontal members that constitute the exposed surface of the ancillary structure.

2. Deck surface area. The test specimen area defined by the overall specimen length and width after assembly.

3. Heat release rate. The net rate of energy release as measured by oxygen depletion calorimetry.

\section{2-7A-4.5 Test assembly.}

1. Size. The overall size of the test deck shall be nominally $24 \times 24$ inches $(610 \times 610 \mathrm{~mm})$ unless width variation of deck boards requires an increase in overall deck width (i.e., the direction of joists) in order to meet the overall dimensions. The length of individual deck boards shall be 24 inches $(610 \mathrm{~mm})$. 
2. Joists. The deck is supported by two nominal $2 \times 6$ Douglas-fir joists running perpendicular to the deck boards, and constructed with a 16-inch $(406 \mathrm{~mm})$ center-to-center spacing. A comparable species that may be more commonly used for structural framing of decks in a given region can be substituted for Douglas-fir.

3. Deck board spacing and fastening. Edge-to-edge spacing and method of attachment shall conform to the manufacturer's installation recommendations. The front deck board shall be flush with the ends of the joists, and the rear deck board shall overhang the end of the joists by 1 inch (25 mm).

3.1. In the absence of recommended installation guidance, the edge-to-edge spacing shall be $\frac{3}{16}$ inch ( $5 \mathrm{~mm}$ ) with boards mechanically attached to the joists using deck screws.

3.2. If nominal 6-inch-wide deck boards are used, a total of 5 boards shall be used for each deck. Changing the board width could change the number of deck boards.

\section{2-7A-4.6 Materials.}

1. Cross-sectional dimension. All deck board materials are to have cross-sectional dimensions equivalent to use in service.

2. Description. The material under test should be described as completely as possible (unit weight, thickness, width, and general information regarding composition).

3. Condition of test material. Prior to testing, all materials (deck boards and joist material) shall be conditioned to a constant weight or for a minimum of 30 days at $73 \pm 4^{\circ} \mathrm{F}\left(23 \pm 2{ }^{\circ} \mathrm{C}\right)$ and 50 $\pm 5 \%$ relative humidity, whichever occurs first. Constant weight shall be defined as occurring when the change in test material weight is less than or equal to 2 percent in a 24-hour period.

\section{2-7A-4.7 PART A. Under-deck flame test.}

\section{2-7A-4.7.1 Equipment.}

1. Burner. A 12 x 12 inch $(300 \times 300 \mathrm{~mm})$ sand diffusion burner shall be used. Natural gas, methane or propane shall be supplied to the burner through a metered control system. The gas supply to the burner shall produce a net heat output of $80 \pm 4 \mathrm{~kW}$ throughout the flame exposure. Burner output can be determined from HRR or calculated from the gas flow rate, temperature, and pressure.

2. Oxygen depletion calorimeter. The equipment shall include a hood, associated ducting, and instrumentation to provide HRR data by oxygen depletion calorimetry.

12-7A-4.7.2 Test system preparation. See Figure No. 1.

1. Deck support assembly. The assembly that holds the test deck over the burner.

2. Baffle panels and joist support. Horizontal metal plates to support the deck joists along their 
full length, and also to confine burner flames to the underside of the deck boards located between the support joists.

3. Back wall. Ceramic fiber board or another noncombustible panel product for the back wall material. Total height of the back wall shall be 8 feet $(2.4 \mathrm{~m})$.

4. Ledger board. A 4-foot-long (1.2 m) simulated 2 x 6 ledger board shall be constructed of layers of ceramic fiber board (or other noncombustible panel product) and attached to the wall at a height slightly below the overhang of the rear deck board of the test deck.

\section{2-7A-4.7.3 Conduct of tests.}

1. Airflow. The test shall be conducted under conditions of ambient airflow.

2. Number of tests. Conduct the test on three replicate assemblies.

3. Burner output verification. Without a deck in the apparatus, set the output of the burner to $80 \pm 4 \mathrm{~kW}$. Conduct a verification run of 3 minutes to ensure the heat release rate, and then turn off the burner.

4. Measurement of heat release rate. HRR is measured during the tests with a properly calibrated oxygen depletion calorimeter. Since HRR is typically a post-test analysis, this criterion for Acceptance may be determined at the end of the test.

5. Burner positioning. Center the burner directly under the middle deck board, midway between the joists. The distance from the top of the burner to the bottom of the deck boards shall be 27 inches $(690 \mathrm{~mm})$.

6. Moisture content. Measure the moisture content of the wooden members of the assembly using a moisture meter (ASTM D 4444).

\section{Procedure.}

7.1 Ignition. Ignite the burner, controlling for a constant $80 \pm 4 \mathrm{~kW}$ output.

7.2. Flame exposure. Continue the exposure for a 3-minute period. Extinguish the burner.

7.3. Continued combustion. Continue observation for an additional 40 minutes or until all combustion has ceased.

8. Observations. Note physical changes of the deck boards during the test, including structural failure of any deck board, location of flaming and glowing ignition, and loss of material (i.e., flaming drops of particles falling from the deck). It is desirable to capture the entire test with a video recorder to allow review of the details of performance.

12-7A-4.7.4 Report. The report shall include a description of the deck board material and the 
time of any degradation (effective net peak heat release rate, structural failure, flaming drops or particles falling from the deck) during the test.

1. Calculated rate of heat release. The effective net peak heat release rate (HRR) shall be calculated as follows:

1.1. During the first 5 minutes of the test (the 3 minutes during which the ignition source burner is operating and the immediately following 2 minutes) the effective net peak HRR of the test assembly shall be reported as: effective net peak HRR = (peak heat release rate - $80 \mathrm{~kW}$ ) / (deck surface area).

1.2. During the remaining test duration the effective net peak heat release rate of the test assembly shall be reported as: effective net peak HRR = (peak heat release rate) $/$ (deck surface area)

12-7A-4.7.5 Conditions of Acceptance. Should one of the three replicates fail to meet the Conditions of Acceptance, three additional tests may be run. All of the additional tests must meet the Conditions of Acceptance.

1. Effective net peak heat release rate of less than or equal to $25 \mathrm{~kW} / \mathrm{ft}^{2}\left(269 \mathrm{~kW} / \mathrm{m}^{2}\right)$.

2. Absence of sustained flaming or glowing combustion of any kind at the conclusion of the 40minute observation period.

3. Absence of falling particles that are still burining when reaching the burner or floor.

\section{2-7A-4.8 PART B. Burning brand exposure.}

\section{2-7A-4.8.1 Equipment.}

1. Wind tunnel. The wind tunnel shall have the capability of providing $12 \mathrm{mph}(5.4 \mathrm{~m} / \mathrm{s})$ airflow over the deck assembly.

2. Anemometer. Device for measuring airflow across the deck.

3. Burner. Gas-fueled burner for brand ignition.

12-7A-4.8.2 Test system preparation. See Figure 2. The ASTM E 108 "A" brand roof test apparatus is to be used, with the following modifications:

1. Deck support. The deck shall be supported horizontally with the center 60 inches $(150 \mathrm{~mm})$ from the front opening of the wind tunnel and the joists parallel to the airflow and resting on two transverse metal supports. The top surfaces of these supports, no more than 3 inches $(75 \mathrm{~mm})$ wide, are at the same height as the floor of the wind tunnel.

2. Fragments. Burning fragments shall be free to fall to the floor of the room. 


\section{2-7A-4.8.3 Conduct of tests.}

1. Number of tests. Conduct the test on three replicate assemblies.

2. Moisture content. Measure the moisture content of the wooden members of the assembly using a moisture meter (ASTM D 4444).

3. Procedure. Adhere to ASTM E 108 "Standard Test Methods for Fire Tests of Roof Coverings" (burning brand test, "A" brand), with apparatus modified as described above in "Test system preparation" and the following procedure:

3.1 The air velocity shall be calibrated using the 60-inch $(1.5 \mathrm{~m})$ framework spacing, with a smooth noncombustible calibration deck at a 5-inch per 12-inch horizontal incline positioned 60 inches $(1.5 \mathrm{~m})$ from the front opening of the wind tunnel. All other measurement details shall be followed as specified in Sections 4.4.2, 4.4.3, and 4.4.4 of ASTM E 108. Although ASTM E 108 specifies calibration to be conducted with the 33inch (840-mm) framework spacing used for the intermittent flame test set up, tests have shown that at the nominal $12 \mathrm{mph}$ setting, there was not difference in measured velocity between the 33- and 60-inch framework spacing.

3.2 Mount the test specimen at a zero horizontal incline positioned 60 inches $(1.5 \mathrm{~m})$ from the front opening of the wind tunnel.

3.3 Ignite the "A" brands as specified in Section 9.4 of ASTM E 108 as reprinted here:

1. Each 12- x 12-inch ( $300 \times 300 \mathrm{~mm}$ ) face for 30 seconds.

2. Each 2.25- x 12-inch ( 57 x $300 \mathrm{~mm}$ ) edge for 45 seconds.

3. Each 12- x 12-inch (300 x $300 \mathrm{~mm}$ ) face again for 30 seconds.

3.4 Center the burning brand laterally on the deck with the front edge 2.5 inches $(64 \mathrm{~mm})$ from the entering air edge of the deck.

3.5 Continue the exposure for a 40-minute period or until all combustion of the deck boards ceases. The test shall be terminated immediately if flaming combustion accelerates uncontrollably (runaway combustion) or structural failure of any deck board occurs.

Heat Release Rate is not monitored because of the impracticability with the specified airflow.

4. Observations. Note physical changes of the deck boards during the test, including deformation from the horizontal plane, location of flaming and glowing combustion, and loss of material (i.e., flaming drops of particles falling from the deck). It is desirable to capture the entire test with a video recorder to allow review of the details of performance.

12-7A-4.8.4 Report. The report shall include description of the deck board material, and the time of any degradation (accelerated combustion, board collapse, flaming drops or particles falling from the deck).

12-7A-4.8.5 Conditions of Acceptance. Should one of the three replicates fail to meet the 
Conditions of Acceptance, three additional tests may be run. All of the additional tests must meet the Conditions of Acceptance:

1. Absence of sustained flaming or glowing combustion of any kind at the conclusion of the 40minute observation period.

2. Absence of falling particles that are still burning when reaching the burner or floor.
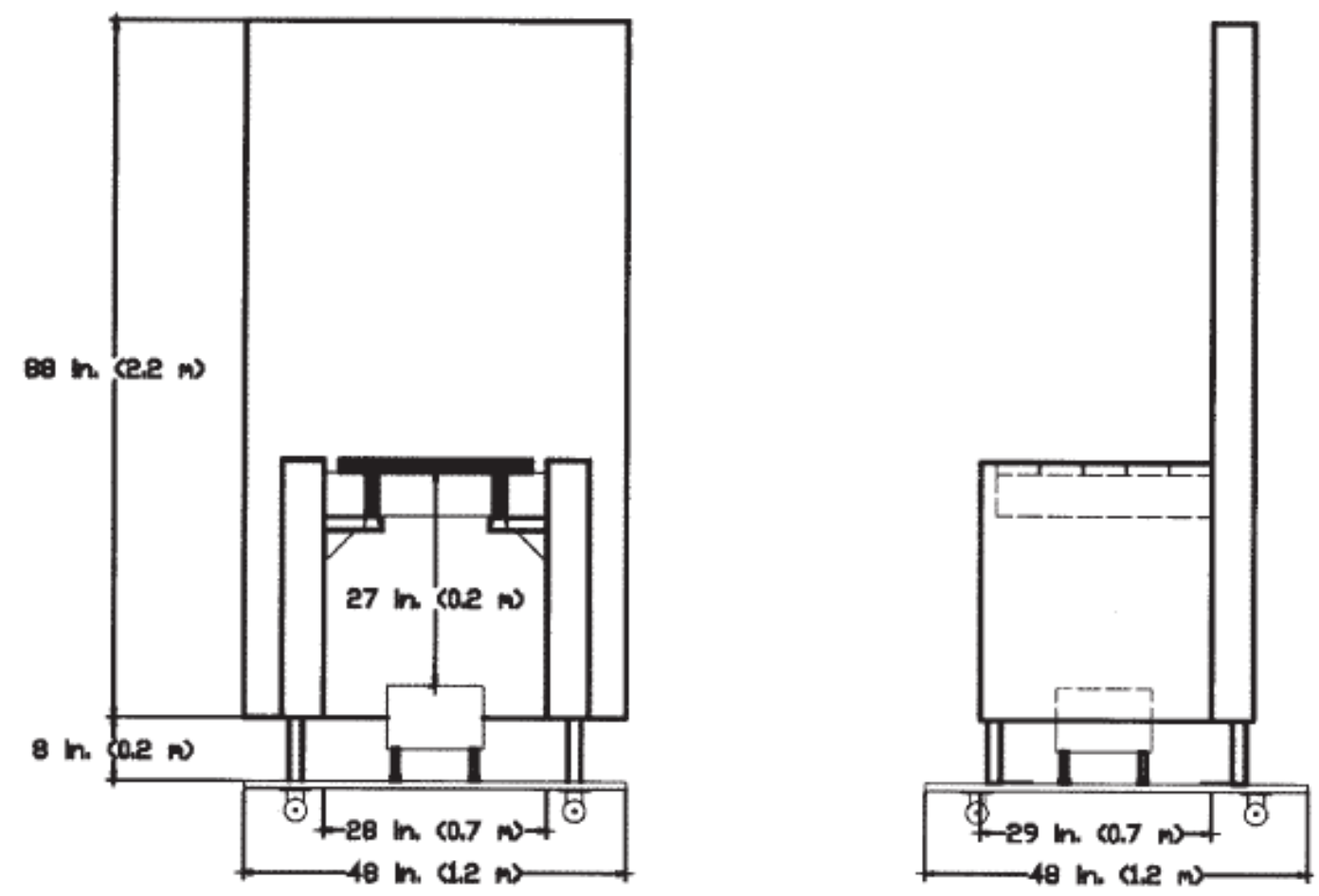

FIGURE 1. DECK TEST ASSEMBLY (UNDER DECK-FLAME)

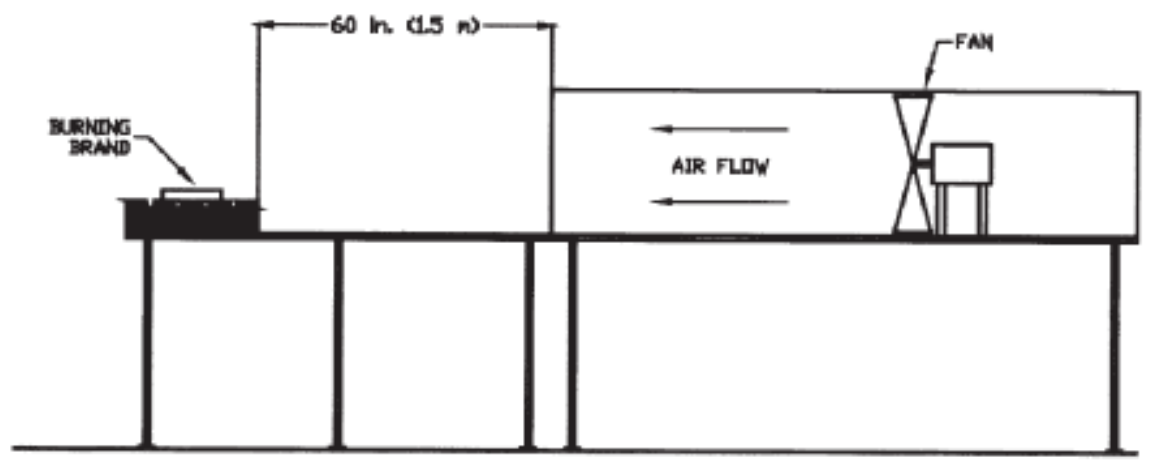

FIGURE 2. DECK TEST ASSEMBLY (BURNING-BRAND) 